OPEN ACCESS

Edited by:

Weiwen Zhang

Tianjin University, China

Reviewed by:

Frank O'Neill Aylward,

Virginia Tech, United States

Lubos Polerecky

Utrecht University, Netherlands

${ }^{*}$ Correspondence:

Maryam Ataeian

maryam.ataeian@ucalgary.ca

Specialty section:

This article was submitted to

Microbiotechnology,

a section of the journal

Frontiers in Microbiology

Received: 20 September 2021

Accepted: 19 January 2022

Published: 11 February 2022

Citation:

Ataeian M, Liu Y, Kouris A

Hawley AK and Strous M (2022)

Ecological Interactions

of Cyanobacteria and Heterotrophs

Enhances the Robustness

of Cyanobacterial Consortium

for Carbon Sequestration.

Front. Microbiol. 13:780346.

do: 10.3389/fmicb.2022.780346

\section{Ecological Interactions of Cyanobacteria and Heterotrophs Enhances the Robustness of Cyanobacterial Consortium for Carbon Sequestration}

\author{
Maryam Ataeian ${ }^{*}$, Yihua Liu' ${ }^{2}$, Angela Kouris ${ }^{1}$, Alyse K. Hawley ${ }^{3}$ and Marc Strous ${ }^{1}$ \\ 1 Department of Geoscience, University of Calgary, Calgary, AB, Canada, ${ }^{2}$ Department Microbiome Science, Max Planck \\ Institute for Developmental Biology, Tübingen, Germany, ${ }^{3}$ School of Engineering, University of British Columbia Okanagan, \\ Kelowna, BC, Canada
}

Lack of robustness is a major barrier to foster a sustainable cyanobacterial biotechnology. Use of cyanobacterial consortium increases biodiversity, which provides functional redundancy and prevents invading species from disrupting the production ecosystem. Here we characterized a cyanobacterial consortium enriched from microbial mats of alkaline soda lakes in BC, Canada, at high pH and alkalinity. This consortium has been grown in open laboratory culture for 4 years without crashes. Using shotgun metagenomic sequencing, 29 heterotrophic metagenome-assembled-genomes (MAGs) were retrieved and were assigned to Bacteroidota, Alphaproteobacteria, Gammaproteobacteria, Verrucomicrobiota, Patescibacteria, Planctomycetota, and Archaea. In combination with metaproteomics, the overall stability of the consortium was determined under different cultivation conditions. Genome information from each heterotrophic population was investigated for six ecological niches created by cyanobacterial metabolism and one niche for phototrophy. Genome-resolved metaproteomics with stable isotope probing using ${ }^{13} \mathrm{C}$ bicarbonate (protein/SIP) showed tight coupling of carbon transfer from cyanobacteria to the heterotrophic populations, specially Wenzhouxiangella. The community structure was compared to a previously described consortium of a closely related cyanobacteria, which indicated that the results may be generalized. Productivity losses associated with heterotrophic metabolism were relatively small compared to other losses during photosynthesis.

Keywords: cyanobacterial consortium, soda lakes, ecological niche, metagenomics, protein/SIP

\section{INTRODUCTION}

Ecological interactions among phototrophs and heterotrophs are at the core of all light-exposed ecosystems and the entry into much of the biological carbon cycling on Earth (Paerl and Pinckney, 1996; Falkowski et al., 1998; Grossart et al., 2006; Azam and Malfatti, 2007). The diversity and complexity inherent to many natural ecosystems presents challenges in defining the ecological 
niches that describe the complex web of these interactions. The assembly of microbial communities and understanding the metabolic roles of each population is an important step to engineering microbial communities to carry out a desired function. Cultivation of a simplified model microbial community, collected from a complex natural ecosystem offers an opportunity to study these metabolic interactions (Beliaev et al., 2014; Aharonovich and Sher, 2016; Biller et al., 2016). For many phototrophic communities, cyanobacteria are the primary producers, capturing solar energy and providing fixed carbon and molecular oxygen to heterotrophic populations. Simplified cyanobacterial consortia, obtained from a complex natural community by selective enrichment, can provide insight into the community assembly processes for productive natural environments (Paerl and Pinckney, 1996; Paerl et al., 2000).

The high growth rate of many cyanobacteria makes them excellent candidates for biotechnology. However, there remain many challenges with the implementation of cyanobacterial technologies at scale. One of these is robustness (Quinn et al., 2012). Cultures that work well in the laboratory may crash in large scale, non-sterile production systems with more variable environmental conditions. This lack of robustness is a major barrier to achieving sustainable and economically feasible biotechnology (Shurin et al., 2013). One potential solution to increase stability and robustness of cyanobacterial biotechnology is to use the benefits of biodiversity by using a designed or naturally occurring cyanobacterial consortium instead of a monoculture (Cole et al., 2014; Duffy et al., 2017; Sharp et al., 2017).

Two fundamental ecological concepts contribute to robustness of microbial consortia (Brockhurst et al., 2007). First, the diverse members of the consortium occupy the various available ecological niches. By filling up the available niches, less resources will be available to invading species and it becomes more difficult for invading organisms to successfully colonize and potentially destabilize the production ecosystem (Moran and Miller, 2007; Jousset et al., 2011; Tan et al., 2015; Gallien and Carboni, 2017). Second, biodiversity among the organisms occupying a niche improves the overall stability of the process by creating functional redundancy (Louca et al., 2018). When variability in environmental conditions or viral attack knocks out one organism, others can take over its function.

In nature, highly productive cyanobacterial mats benefit from mutualistic phototroph-heterotroph interactions that are based on nutrient cycling (Christie-Oleza et al., 2017). These interactions occur in a context of recurring ecological niches, as shown by specific and conserved diurnal gene expression patterns of marine heterotrophs (Aylward et al., 2015). Phototrophs produce large amounts of dissolved organic matter (DOM) which is the main source of carbon and energy for the heterotrophs (McCarren et al., 2010). Some of this organic matter is excreted as fermentation products such as formate, acetate, lactate, ethanol, and $\mathrm{H}_{2}$ at night (Stal and Moezelaar, 1997). Low molecular weight carbohydrates and free amino acids can be released as osmolytes following osmotic shock (Reed et al., 1986; Hagemann, 2011). Organic matter can also be released in the form of outer membrane lipid vesicles containing proteins, DNA, and RNA
(Biller et al., 2014). Finally, organic matter can be released by lysis of cyanobacterial cells, for example, due to viral attack by cyanophages (Puxty et al., 2018). Some Bacteroidetes have been shown to feed on remains of dead cyanobacterial cells (Ben Hania et al., 2017). Some Planctomycetes and Verrucomicrobia encode glycoside hydrolases and sulfatases in their genomes (Orellana et al., 2021). These enzymes become highly expressed in response to availability of sulfated polysaccharides, suggesting the ability of these species to use sulfated glycopolymers, part of the cyanobacterial cell wall, as a carbon source (De Philippis et al., 1998; Wegner et al., 2013; Spring et al., 2016).

In return, heterotrophs may benefit phototrophs by remineralizing DOM. DOM mostly consists of large molecules called biopolymers. Most microorganisms, including cyanobacteria, are unable to import and process these biopolymers. Heterotrophic bacteria remineralize biopolymers with extracellular enzymes, recycling essential elements contained in these molecules to primary producers. For example, phototrophs benefit from released and recycled nitrogen, phosphorus, and metals (Azam, 1998; Pedler et al., 2014; Christie-Oleza et al., 2015, 2017). Some heterotrophs can also harvest solar energy not used by cyanobacteria as supplementary energy source using Bacteriochlorophyll (Croce and Van Amerongen, 2014) or Proteorhodopsins (Gómez-Consarnau et al., 2007). Heterotrophs also protect phototrophs against opportunistic predators using a range of target-specific inhibitors such as antibacterial (James et al., 1996), anti-larval (Holmström et al., 1992), antialgal (Egan et al., 2001), or antifungal (Franks et al., 2006) molecules. Some Gammaproteobacteria facilitate iron uptake by producing siderophores that bind iron and increase its solubility (Amin et al., 2009; D’Onofrio et al., 2010). Exogenous sources of essential vitamins such as cobalamin (vitamin B12), thiamine (vitamin B1), and biotin (vitamin B7) have been shown to be essential to many marine microalgal species (Croft et al., 2005, 2006; Sañudo-Wilhelmy et al., 2012). Mathematical models have proposed various strategies for delivery of these vitamins, including symbiotic interactions (Thompson et al., 2012; Grant et al., 2014) or passive delivery through the marine microbial loop where nutrients and vitamins from lysed cells in deep water move to the photic zone by upwelling (Karl, 2002). Sulfitobacter species promote diatom cell division by providing growth factors such as indole-3-acetic acid (Amin et al., 2015). Some Sulfitobacter, Colwellia, and Pibocella species have been shown to reduce oxidative stress by producing catalase, superoxide dismutase and glutathione reductase in the vicinity of diatoms and Prochlorococcus bacteria (Hünken et al., 2008; Morris et al., 2008).

Since in biotechnology, cyanobacteria are generally provided with excess nutrients and vitamins, ecological interactions improving nutrient availability are less relevant in that context. While cultivating cyanobacteria in a community may improve robustness, it also potentially decreases biomass yield and productivity because of the conversion of cyanobacterial biomass into heterotrophic biomass. For aerobic heterotrophs, for every carbon atom they assimilate, they respire up to one additional carbon atom as a source of energy (Roller and Schmidt, 2015). Therefore, the overall productivity may be reduced due to 
heterotrophic catabolism. On the other hand, it is unclear whether cyanobacterial pure cultures are able to convert all the produced carbon into cellular biomass. Overflow of fermentation products (Cano et al., 2018), release of osmolytes (Hagemann, 2011), and remains of dead cells (Aguilera et al., 2021) are examples of organic carbon produced by cyanobacteria that may remain unused. These unused resources provide opportunities for successful invasion of cultivation systems, ultimately leading to a culture crash (Shelef and Soeder, 1980; Forehead and O'Kelly, 2013).

We previously enriched a cyanobacterial consortium from microbial mats of four alkaline soda lakes in BC, Canada, at high $\mathrm{pH}$ and alkalinity (Sharp et al., 2017). These soda lakes harbor diverse communities of microorganisms, supporting the growth of high cell density phototrophic mats (Brady et al., 2013). Recently, a core microbiome of $<100$ shared bacterial lineages was described for Canadian and Asian soda lake systems (Vavourakis et al., 2018; Zorz et al., 2019). Although each lake has a different microbial community structure, a nearly identical cyanobacterial consortium was enriched from each lake in laboratory photobioreactors (PBRs) (Sharp et al., 2017). More than $80 \%$ of the consortium consisted of a Candidatus Phormidium alkaliphilum (Ataeian et al., 2021) maintaining a high and robust biomass productivity of $15.2 \pm 1.0 \mathrm{~g} / \mathrm{m}^{2} /$ day (Ataeian et al., 2019) during 4 years of crash-free growth in open laboratory culture.

Here we investigated the niche partitioning within the Ca. P. alkaliphilum consortium and adaptation to different PBRs with different $\mathrm{pH}$ and nitrogen sources (ammonium, urea, and nitrate) using genomics and proteomics. Based on the literature reviewed above, we postulated, a priori, six ecological niches for the consortium's heterotrophs and assigned each heterotroph to one of these niches based on its observed gene content. The niches were: (1) phototrophy, use of (2) fermentation products, (3) compatible solutes, (4) storage compounds, (5) polysaccharides of the cyanobacterial cell wall, and (6) predation of cyanobacteria. Stable isotope probing with ${ }^{13} \mathrm{C}$-labeled bicarbonate, followed by proteomics (protein/SIP) was used to determine the flow of carbon in the consortium. We compared the community structure to a previously described bacterial consortium containing a closely related cyanobacterium. Potential biomass productivity losses associated with heterotrophic catabolism were estimated based on metagenomes and proteomes.

\section{MATERIALS AND METHODS}

\section{Cultivation of Cyanobacterial Consortium and Sample Preparation}

From microbial mats growing in alkaline soda lakes located in BC, Canada (Sharp et al., 2017), a cyanobacterial consortium was enriched in a set of planar PBRs using medium "low-pH ammonium" (see below and Ataeian et al., 2019).

After 1 year of enrichment, the culture was transferred to tubular PBRs and was grown as biofilms on a mesh (Supplementary Figure 14A). Four sets of tubular PBRs were maintained, each with a different medium ("high-pH nitrate," "high-pH urea," "low-pH nitrate" and "low-pH ammonium," see below) to compare biomass growth rates, as previously described (Ataeian et al., 2019). Briefly, 4 L of growth medium was circulated through each $2 \mathrm{~L}$ tubular PBRs at a flow rate of $10 \mathrm{~mL} / \mathrm{min}$. Daily measurements were performed for $\mathrm{pH}$, soluble nitrogen species, bicarbonate, and carbonate concentrations. Depletion of soluble nitrogen in the medium after four to 5 days of cultivation was used to determine the harvesting time for the biomass. Once the growth cycle was completed, the accumulated biomass was manually detached and washed off the mesh, until no visible biomass remained. The next growth cycle was inoculated with $10 \%$ of the harvested biomass. Part of the harvested biomass was immediately frozen at $-80^{\circ} \mathrm{C}$ for genomic and proteomic analyses.

For all four experiments, the growth medium contained: $\mathrm{K}_{2} \mathrm{HPO}_{4}(1.44 \mathrm{mM}), \quad \mathrm{MgSO}_{4} \cdot 7 \mathrm{H}_{2} \mathrm{O}(1 \mathrm{mM}), \mathrm{CaCl}_{2} \cdot 2 \mathrm{H}_{2} \mathrm{O}$ (0.17 mM), $\mathrm{KCl}(6 \mathrm{mM}), \mathrm{NaCl}(0.43 \mathrm{mM})$, ferric ammonium citrate $(10 \mathrm{mg} / \mathrm{L})$, and $1 \mathrm{~mL} / \mathrm{L}$ of trace metal solution containing: Titriplex III (EDTA) (500 mg), $\mathrm{FeSO}_{4} .7 \mathrm{H}_{2} \mathrm{O}(200 \mathrm{mg})$, $\mathrm{ZnSO}_{4} .7 \mathrm{H}_{2} \mathrm{O}(10 \mathrm{mg}), \mathrm{MnCl}_{2} .4 \mathrm{H}_{2} \mathrm{O}(3 \mathrm{mg}), \mathrm{H}_{3} \mathrm{BO}_{3}(30 \mathrm{mg})$, $\mathrm{CoCl}_{2} \cdot 6 \mathrm{H}_{2} \mathrm{O}(20 \mathrm{mg}), \mathrm{CuCl}_{2} \cdot 2 \mathrm{H}_{2} \mathrm{O}(1 \mathrm{mg}), \mathrm{NiCl}_{2} \cdot 6 \mathrm{H}_{2} \mathrm{O}(2 \mathrm{mg})$, $\mathrm{Na}_{2} \mathrm{MoO}_{4} \cdot 2 \mathrm{H}_{2} \mathrm{O}(3 \mathrm{mg})$ per $1,000 \mathrm{~mL}$ of solution. Cultures were grown in duplicates under four different $\mathrm{pH}$ and nitrogen source conditions: low- $\mathrm{pH}$ ammonium (4 $\mathrm{mM} \mathrm{NH}_{4} \mathrm{Cl}$, initial $\mathrm{pH}$ 8.3), low-pH nitrate $\left(1 \mathrm{mM} \mathrm{NH}_{4} \mathrm{Cl}, 3 \mathrm{mM} \mathrm{NaNO}_{3}\right.$, initial $\mathrm{pH} 8.3$ ), high-pH nitrate $\left(1 \mathrm{mM} \mathrm{NH}_{4} \mathrm{Cl}, 3 \mathrm{mM} \mathrm{NaNO}_{3}\right.$, initial $\left.\mathrm{pH} 10.4\right)$, high-pH urea (1 $\mathrm{mM} \mathrm{NH}_{4} \mathrm{Cl}, 3 \mathrm{mM}$ Urea, initial $\mathrm{pH} 10.4$ ). Sodium bicarbonate and sodium carbonate concentrations were mixed to adjust the initial pH of the medium (low-pH: $460 \mathrm{mM}$ $\mathrm{NaHCO}_{3}$ and $20 \mathrm{mM} \mathrm{Na}_{2} \mathrm{CO}_{3}$, high-pH: $35 \mathrm{mM} \mathrm{NaHCO}_{3}$ and $230 \mathrm{mM} \mathrm{Na} \mathrm{CO}_{3}$ ). All experiments where performed at $\sim 25^{\circ} \mathrm{C}$. Light was provided with full spectrum LED lights (Model T5H0; 6400K, Sunblaster Holdings ULC, Langley, BC, Canada) using a $16 \mathrm{~h}: 8 \mathrm{~h}$ light to dark cycle.

Following the 2 years of cultivation in tubular PBRs, biomass grown in "high-pH nitrate" medium showed the highest growth rate and was transferred to a set of stirred $10 \mathrm{~L}$ glass bottle PBRs with "high-pH nitrate" medium (Supplementary Figure 14B). These PBRs were stirred at 300-330 RPM as previously described (Ataeian et al., 2021). In these systems, the biomass grew as small biomass aggregates that rapidly co-aggulated during harvesting, after the stirrer was stopped. The final DNA sample used was taken 1 year after the transfer to the stirred PBR.

\section{Shotgun Metagenome Sequencing and Data Processing}

For the tubular bioreactors, genomic DNA was extracted from the harvested biomass using FastDNA SPIN Kit for Soil protocol (MP Biomedicals, Santa Ana, CA, United States). The protocol provided by the manufacturer was used with minor modifications; the centrifugation time was raised to $10 \mathrm{~min}$ and 5.5 M guanidine thiocyanate was used for additional purification steps. DNA concentrations were measured using a Qubit 2.0 fluorometer (Thermo Fisher Scientific, Canada). Metagenomic library preparation and DNA sequencing was conducted at the 
Center for Health Genomics and Informatics in the Cumming School of Medicine, University of Calgary. DNA was sequenced paired end $2 \times 150$ bp with a 300 cycle mid-output reagent cartridge on the Illumina NextSeq 500 sequencer. The samples were sheared to approximately $350 \mathrm{bp}$ via Covaris sonication, and the libraries were prepared with NEB Ultra II library preparation kit. After adaptor ligation, the average library sizes ranged from 471-483 bp. The adaptors were the NEBNext Multiplex Oligos for Illumina Set 1 and Set 2. Raw reads were passed through an in-house quality control program to cut primers and adapters as well as filter out artifacts and low-quality reads as previously described (Saidi-Mehrabad et al., 2013; Kleiner et al., 2017). After read quality control, 45,308,504, 42,813,618, 43,709,454, and 41,705,594 reads remained for the low-pH ammonium, low- $\mathrm{pH}$ nitrate, high- $\mathrm{pH}$ nitrate, and high- $\mathrm{pH}$ urea datasets, respectively. BBmerge was used with default setting to merge the overlapping reads. Reads from all four samples were combined and assembled into contigs using MEGAHIT v1.0.3 (Li et al., 2016). Contigs of $<500$ bp were discarded. Sequencing coverage was estimated by mapping reads from quality controlled fastq files to assembled contigs using BBMap. Contigs were binned into Metagenome-Assembled-Genomes (MAGs) using MetaBAT version 2.12.1 with following options “-a depth.txt -saveTNF saved_2500.tnf -saveDistance saved_2500.dist -v -superspecific B 20 -keep" (Kang et al., 2015). MAGs were further assessed for contamination and completeness using CheckM version 1.0.8 (Parks et al., 2015). GTDBtK was used for classification of the MAGs (Parks et al., 2018). MetaErg was used for annotation of the MAGs (Dong and Strous, 2019). fastANI (Jain et al., 2018) was used for comparison of MAGs across samples to MAGs previously obtained from Kulunda soda lakes (Vavourakis et al., 2018) and Cariboo Plateau soda lakes (Zorz et al., 2019). $16 S$ rRNA gene sequences were obtained with hyloFlash $2^{1}$ and were associated with MAGs based on phylogeny and sequencing coverage. Genes for production of secondary metabolites were identified with antiSMASH (Blin et al., 2019).

Genomic DNA was also extracted from stirred PBRs. DNA was extracted from pelleted biomass using a modified version of the FastDNA SPIN Kit for Soil protocol (MP Biomedicals) as previously described (Costa et al., 2009), with minor modifications. The samples were processed in a bead beater twice for $30 \mathrm{~s}$ at setting $4.5 \mathrm{~m} / \mathrm{s}$. To prepare the genomic DNA sequencing library, the Nextera DNA Flex Library Prep protocol (Illumina) was used following the manufacturer's protocol. Shotgun metagenomic sequencing $(2 \times 300 \mathrm{bp})$ was performed using an Illumina MiSeq sequencer. Read quality control and assembly was performed as described in Ataeian et al. (2021).

\section{Phylogenetic Analysis}

The GTDB tool kit with function classify_wf was used to construct all the phylogenetic trees (Parks et al., 2018). All 91 MAGs recently obtained from the original Cariboo mats (Zorz et al., 2019) and 871 MAGs from sediments of the Kulunda Steppe (Vavourakis et al., 2018) as well as all 18 MAGs from Phormidium OSCR consortium were included as reference sequences. gtdbtk

${ }^{1}$ http://github.com/HRGV/phyloFlash classify_wf was used for taxonomic classification of genomes. After pplacer process all the provided genomes and finds the maximum-likelihood placement of each genome in the Genome Taxonomy DataBase Toolkit (GTDB-Tk) reference tree, the individual trees were reconstructed. phyloFlash_compare.pl was used for clustering in Figure 1. Samples were clustered by their similarity in terms of taxonomic content.

\section{Protein Extraction, Peptide Preparation, and Metaproteomics}

Protein was extracted from biomass from tubular PBRs. Four technical replicates were used for each condition. SDT-lysis buffer (0.1 M DTT) was added to lysing matrix bead tubes A (MP Biomedicals) containing PBR biomass in a 10:1 ratio. Tubes were bead-beated in an OMNI Bead Ruptor 24 for $45 \mathrm{~s}$ at $6 \mathrm{~ms}^{-1}$. Then tubes were incubated at $95^{\circ} \mathrm{C}$ for $10 \mathrm{~min}$, spun down for 5 min at $21,000 \times g$ and tryptic peptides were isolated from pellets by filter-aided sample preparation (FASP) (Wisniewski et al., 2009) with modification from Hamann et al. (2016). One-dimensional LC-MS/MS using a block-randomized design (Oberg and Vitek, 2009) was performed. For each run, $1200 \mathrm{ng}$ of extracted peptides were loaded onto a $5 \mathrm{~mm}, 300 \mu \mathrm{m}$ ID C18 Acclaim ${ }^{\circledR}$ PepMap100 pre-column (Thermo Fisher Scientific) using an UltiMate ${ }^{\mathrm{TM}} 3000$ RSLCnano Liquid Chromatograph (Thermo Fisher Scientific) and desalted on the pre-column. Peptides were separated on a $50 \mathrm{~cm} \times 75 \mu \mathrm{m}$ analytical EASYSpray column packed with PepMap RSLC $\mathrm{C}_{18}, 2 \mu \mathrm{m}$ material (Thermo Fisher Scientific). The analytical column was connected directly to the Q Exactive Plus hybrid quadrupole-Orbitrap mass spectrometer (Thermo Fisher Scientific) via an Easy-Spray source. Peptides were separated on the analytical column at a flow rate of $225 \mathrm{~nL} / \mathrm{min}$ using a $260 \mathrm{~min}$ gradient and mass spectra acquired in the Orbitrap (Petersen et al., 2016).

Expressed proteins were identified and quantified with Proteome Discoverer version 2.0.0.802 (Thermo Fisher Scientific), using the Sequest HT node as described previously (Petersen et al., 2016). The protein-level false discovery rate (FDR) was restricted to below 5\% (FidoCT $q$-value $<0.05$ ) (Serang et al., 2010) for high confidence identifications (FidoCT $q$-value $<0.01$ ) and medium confidence identifications (FidoCT $q$-value $0.01-0.05$ ).

Relative protein abundances were estimated based on normalized spectral abundance factors (NSAFs) method (Florens et al., 2006). Abundances of MAGs in the metaproteome were estimated by dividing the sum of the relative abundances for all of its expressed proteins by the sum of the relative protein abundances for all expressed proteins. The identification database was created using predicted protein sequences of binned and unbinned contigs, after filtering out highly similar proteins (>95\% amino acid identity) with cd-hit (Li and Godzik, 2006). The cRAP protein sequence database $e^{2}$ of common laboratory contaminating proteins were added to the final database. In total 11,426 proteins were identified. After removing the proteins identified as cyanobacterial, the rest was used. The number of proteins was reduced by only including proteins that had at

${ }^{2}$ http://www.thegpm.org/crap/ 


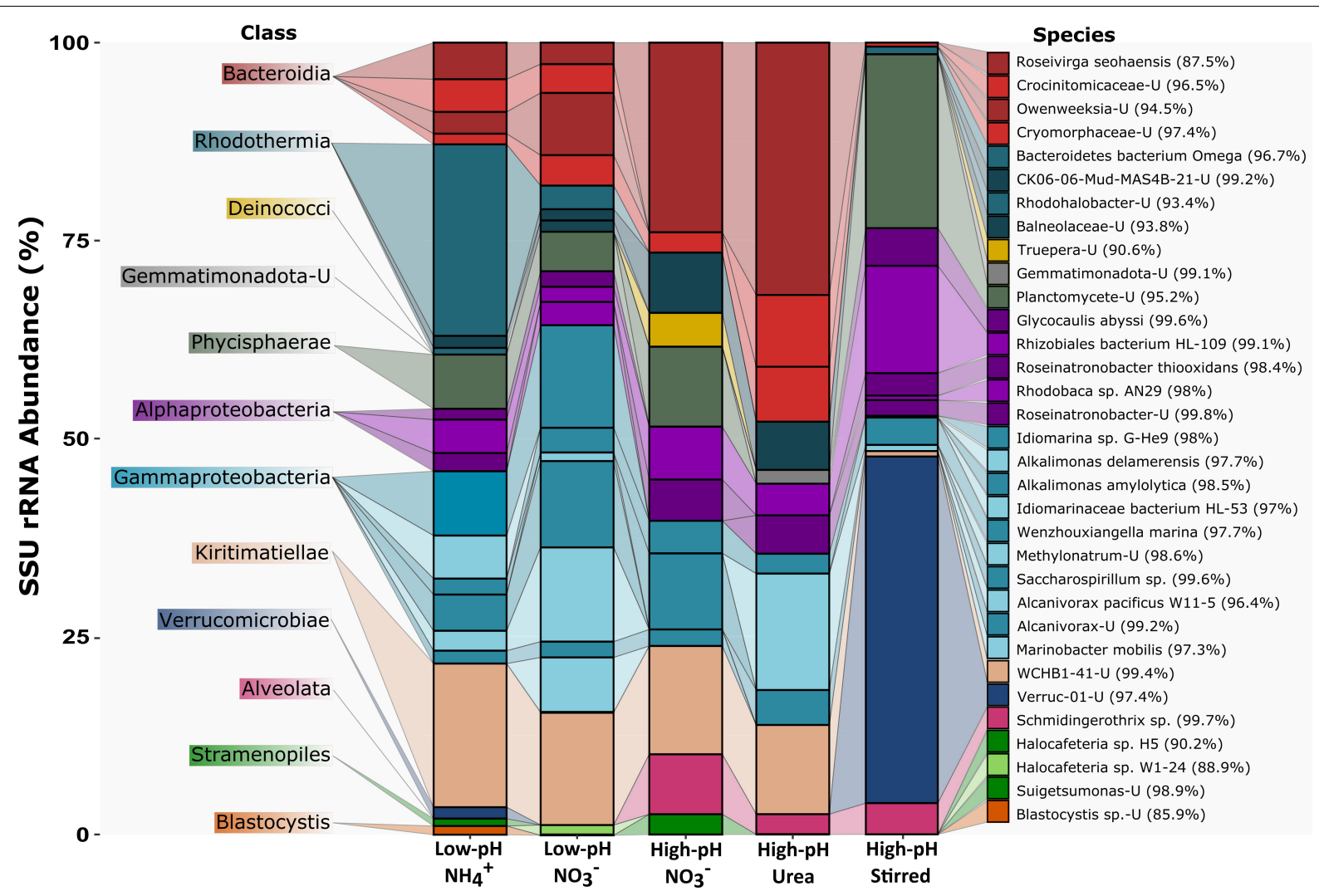

FIGURE 1 | Community structure of the heterotrophs in the Candidatus "Phormidium alkaliphilum" consortium based on SSU rRNA extracted from metagenomes. The figure shows the abundance and taxonomic classification of populations as determined by phyloFlash. The classification is shown at class (left) and species (right) level. The percentage identity to the reference species is shown next to each species. Candidatus "Phormidium alkaliphilum," $>72 \%$ abundant in all experiments, is not shown. Despite its name, Bacteroidetes bacterium Omega, is affiliated with Rhodothermia. Data in Supplementary Table 1.

least four NSAF values greater than 0 in all replicates of one condition. The mass spectrometry proteomics data have been deposited to the ProteomeXchange Consortium via the PRIDE (Perez-Riverol et al., 2019) partner repository with the dataset identifier PXD024393.

\section{${ }^{13} \mathrm{C}$ Labeled Proteomics}

Proteomics was carried out on the stirred bioreactor cyanobacterial consortia. $2.0 \mathrm{~mL}$ of consortia was transferred from $2 \mathrm{~L}$ stirred bioreactors into $100 \mathrm{~mL}$ glass bottles containing $50 \mathrm{~mL}$ of culture media in duplicate. $2.68 \mathrm{~mL}$ of $0.1 \mathrm{M} \mathrm{NaH}^{13} \mathrm{CO}_{3}$ was added for a total concentration of $0.536 \mathrm{M} \mathrm{NaHCO}_{3}$ containing $2 \%{ }^{13} \mathrm{C}$ (including the $\sim 1 \%$ natural abundance, background ${ }^{13} \mathrm{C}$ ). Cultures were subjected to day/night cycles of 16:8 h, using full spectrum LED lights (Model T5H0; 6400K, Sunblaster Holdings ULC, Langley, BC, Canada). The initial sample was taken directly from the $2 \mathrm{~L}$ stirred bioreactor. Time course samples were taken at $14 \mathrm{~h}$ (end of day 1), $22 \mathrm{~h}$ (end of night 1), $36 \mathrm{~h}$ (end of day 2), and $44 \mathrm{~h}$ (end of night 2). The $1 \mathrm{~mL}$ sample was centrifuged, supernatant media was removed, and the resulting pellet was frozen at $-80^{\circ} \mathrm{C}$ for $\sim 10$ days until protein extraction. Protein extraction was carried out as described above.
Extracted peptides were separated by an RSLC-nano Liquid Chromatograph (Thermo Fisher Scientific, Waltham, MA, United States), and subsequently analyzed on a QExatcive Plus hybrid quadrupole Orbitrap mass spectrometer (Thermo Fisher Scientific). Quadruplicate technical replicates were run as described above. Identification and quantification of detected proteins were carried out in Proteome Discover version 2.2.0.388 (Thermo Fisher Scientific) using the SEQUEST HT node. FDR were estimated at the peptide and protein level with Percolator Node and FidoCT, respectively and proteins and peptides with FDR $>5 \%$ discarded from further analysis. Proteins without protein-unique peptides were discarded. Protein database consisted of metagenome assembled genomes from the cyanobacterial consortia in this study. The ${ }^{13} \mathrm{C} /{ }^{12} \mathrm{C}$ of detected peptides were determined with Calis-p 2.0 software (Kleiner et al., 2021), using scored peptide spectra match (PSM) tables and raw MS data (in mzML format) as input ${ }^{3}$.

The ${ }^{13} \mathrm{C} /{ }^{12} \mathrm{C}$ ratio for each peptide mapping to a single MAG was attributed to the Taxonomy for that MAG. For peptides mapping to multiple MAGs the ratio was attributed to the most specific taxonomic level common to the protein taxonomic assignments. E.g., Peptides assigned to Verrucomicrobiota,

\footnotetext{
${ }^{3}$ https://sourceforge.net/p/calis-p/wiki/Home/
} 
Opitutales consist of MAGs 7A and 56, peptides assigned to Verrucomicrobiota, Kritimatiellae consist of MAGs 17 and 41, and peptides assigned to Saccharospirillaceae consist of MAGs $5 \mathrm{~A}$ and 23.

The ${ }^{13} \mathrm{C} /{ }^{12} \mathrm{C}$ ratio for each taxon at a given time point was calculated as the median ratio of all peptides mapping to a given taxa weighted by the spectral intensity of that peptide in that sample using Hmisc 3.6.3 in R 3.6.2. Weighting of the ratio by spectral intensity accounts for the amount of that peptide detected, better reflecting the abundance of peptides with a given ratio. For cyanobacteria and heterotrophs (all peptides not mapped to Cyanobacteria), boxplots show the median ${ }^{13} \mathrm{C} /{ }^{12} \mathrm{C}$ ratio with upper and lower quantiles. For individual MAGs, in addition, individual points showing the ${ }^{13} \mathrm{C} /{ }^{12} \mathrm{C}$ ratio for each detected peptide at each time point were plotted to visualize the distribution and number of peptides detected. The mass spectrometry proteomics data have been deposited to the ProteomeXchange Consortium via the PRIDE (Perez-Riverol et al., 2019) partner repository with the dataset identifier PXD028578.

\section{RESULTS AND DISCUSSION}

\section{Metagenomics Reveals the Overall Stability of the Consortium}

Previously, we enriched a cyanobacterial consortium in laboratory photobioreactors (PBRs) (Ataeian et al., 2019) from microbial mats of four alkaline soda lakes located on Cariboo Plateau, BC, Canada (Brady et al., 2013; Zorz et al., 2019). Recently, we introduced Candidatus "Phormidium alkaliphilum," the most abundant member and the only cyanobacterium in the consortium (Ataeian et al., 2021). Here, we focus on the roles of the heterotrophic members of the consortium. For this, we made use of five metagenomes, collected from different cultures and time points as previously described (Ataeian et al., 2021). Two cultures had an initial pH of 8.3 (low-pH), one received ammonium as the nitrogen source, the other nitrate. Two cultures had an initial $\mathrm{pH}$ of 10.4 (high-pH), one received nitrate as the nitrogen source, the other urea. These cultures were maintained as biofilms in tubular PBRs. The fifth metagenome was obtained 2 years later from a stirred $\mathrm{PBR}$. In this final PBR, the culture grew at an initial $\mathrm{pH}$ of 10.4 , as small flocs or aggregates. This culture was seeded from the high-pH-nitrate culture. The medium of all five cultures always remained the same containing $0.5 \mathrm{~mol} / \mathrm{L}$ of combined bicarbonate and carbonate at a starting $\mathrm{pH}$ of 8.3 or 10.4. During 5 days of growth, the $\mathrm{pH}$ increased, up to 11.2 in the high-pH experiments. No culture crashes were ever observed over the years of cultivation and the system showed robust and rapid growth with $15.2 \pm 1.0 \mathrm{~g} / \mathrm{m}^{2} /$ day biomass productivity (Sharp et al., 2017; Ataeian et al., 2019).

To compare the community structure of the consortium for all five cultures, we used phyloFlash to reconstruct full length small subunit ribosomal RNA (SSU/16S rRNA) gene sequences from short Illumina reads (Gruber-Vodicka et al., 2019). The obtained full length SSU rRNA sequences enable taxonomic classification of the most abundant members of the consortium. This way, we determined the community structure for each of the five PBSs. In the low-pH tubular PBRs, $>72 \%$ of the SSU rRNA reads recovered by phyloFlash were associated with Candidatus "Phormidium alkaliphilum." This number increased to $>87 \%$ in high-pH tubular PBR. After 2 years of growth in the stirred PBR at high-pH, 76.3\% of the SSU rRNA reads were assigned to $C a$. P. alkaliphilum. The remainder of the communities was associated with 28 Bacterial and 5 Eukaryote populations. The heterotrophs were classified to Bacteroidota, Deinococcota, Gemmatimonadota, Planctomycetota, Proteobacteria, and Verrucomicrobiota (Figure 1 and Supplementary Table 1). The Eukaryotic species were all affiliated with SAR (Stramenopiles, Alveolates, and Rhizaria) clade.

The apparent low diversity of the stirred culture is an artifact caused by the much lower sequencing coverage of its metagenome (Ataeian et al., 2021; Supplementary Table 3). Because of the lower number of reads, fewer complete $16 \mathrm{~S}$ rRNA genes were assembled. For biodiversity analysis, reads from the stirred PBR were mapped to all the complete $16 \mathrm{~S}$ rRNA genes collected from tubular PBRs.

At high $\mathrm{pH}$, diversity among heterotrophs was lower, and less redundancy was observed within species of the same class (10 heterotrophic species were detected in high-pH cultures while 18 species were detected in low-pH cultures) (Supplementary Table 1). The abundance of Bacteroidia, Deinococcota, Gemmatimonadota, and Alveolata was higher at high-pH. Gammaproteobacteria were more abundant at low$\mathrm{pH}$ (Figure 1 and Supplementary Table 1). Five eukaryotic species were detected. A species related to Schmidingerothrix from the order Ciliophora showed high abundance at high-pH (Figure 1 and Supplementary Table 1). Schmidingerothrix is a slender hypotrich ciliate which prefers a saline environment and feeds on bacteria (Foissner, 2012). Two species related to Blastocystis and Halocafeteria were more abundant at low$\mathrm{pH}$ (Figure $\mathbf{1}$ and Supplementary Table 1). Blastocystis is a unicellular protist known to occur in the intestines of animals (Tan, 2008). Halocafeteria is a heterotrophic nanoflagellate frequently observed in hypersaline environments and feeds on prokaryotes (Park et al., 2006).

\section{Niche Partitioning Among Heterotrophic Consortium Members}

After comparing community structures with phyloFlash, we assembled and binned sequencing reads from all four 2018 metagenome samples to obtain MAGs of the most abundant (Supplementary Table 1) species of the consortium. We recovered 30 MAGs with completeness $>90 \%(n=27)$ and contamination $<4 \%(n=28)$. The GTDB-Tk (Parks et al., 2018) was used for taxonomic classification of all the MAGs (Figure 2 and Supplementary Table 2). In addition to the Cyanobacterium, $\mathrm{Ca}$. P. alkaliphilum, each community was composed of at least 10 Bacteroidota, 3 Alphaproteobacteria, 9 Gammaproteobacteria, 4 Verrucomicrobiota, 1 Patescibacteria, 1 Planctomycetota, and 1 Archaea (Figure 2 and Supplementary Table 1). These classifications were consistent with phyloFlash 


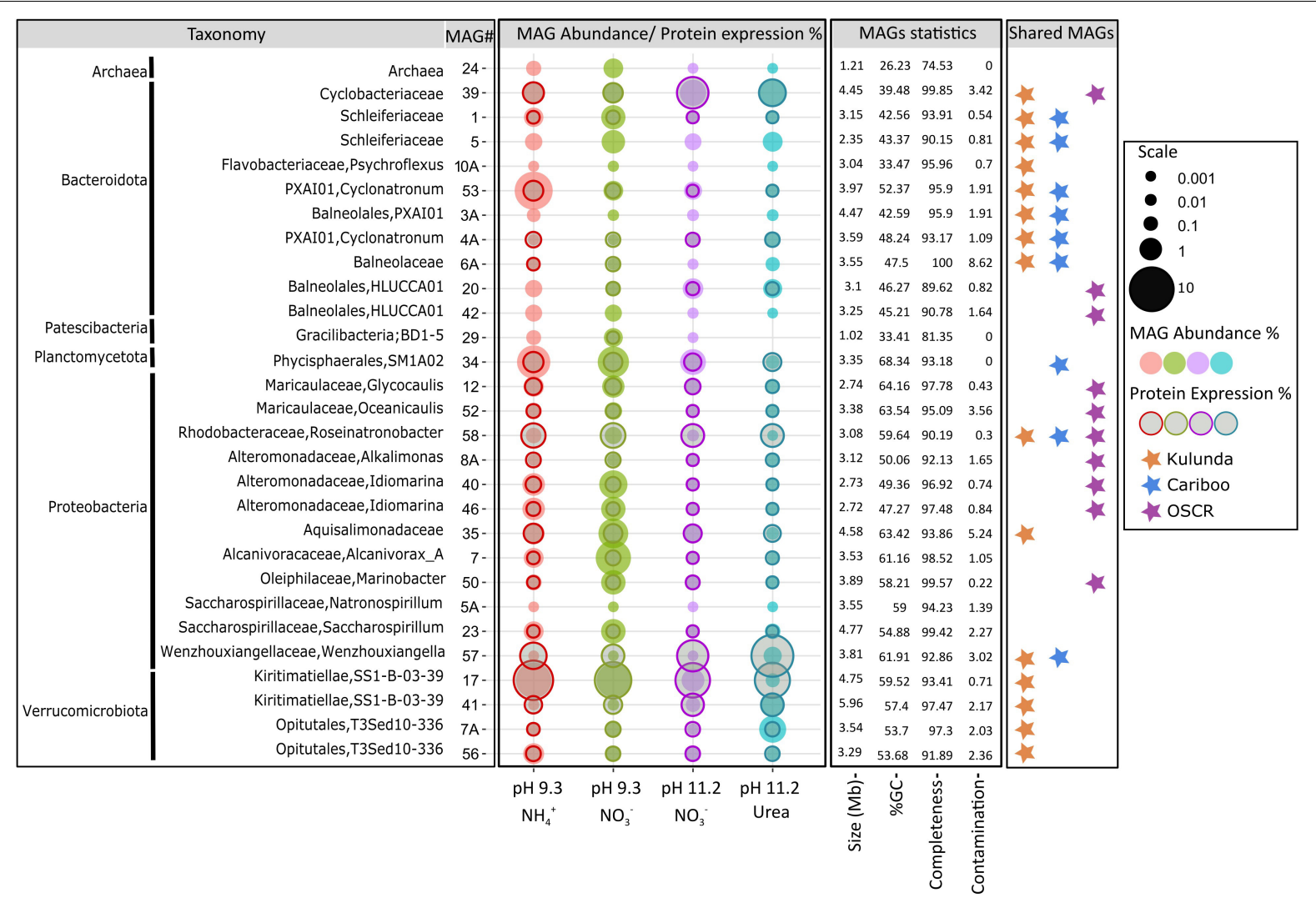

FIGURE 2 | Taxonomy, relative abundance, and protein expression of the heterotrophic MAGs obtained from the Candidatus "Phormidium alkaliphilum" consortium. Taxonomic classifications are according to GTDBtk. Bubble plot showing abundances based on DNA sequencing and proteomics in four experiments with different $\mathrm{pH}$ and nitrogen sources. MAGs clustering at either family or genus level with Cariboo and Kulunda soda lakes MAGs as well as MAGs from the previously described Phormidium OSCR consortium are shown with stars. Data in Supplementary Tables 1, 2.

results presented above, with three exceptions. One species of Deinococcota and one from Gemmatimonadota were binned into MAGs with completeness of less than $70 \%$ and were not analyzed further. Next, the 16S rRNA gene of the Patescibacteria MAG was not obtained by phyloFlash. Apart from that, all other MAGs could be matched to a $16 \mathrm{~S}$ rRNA gene obtained from phyloFlash and the relative abundance profiles were fairly similar between the two analyses.

We also used GTDB-tk to assess the similarity of the PBR MAGs to 91 MAGs recently obtained from the original Cariboo mats (Zorz et al., 2019) and 871 MAGs from sediments of the Kulunda Steppe soda lakes (Figure 2 and Supplementary Table 2). Eight PBR MAGs clustered with both Cariboo and Kulunda lake MAGs at either family or genus level (Supplementary Figures 1-13) and were part of the core soda-lake microbiome identified by Zorz et al. (2019). Seven MAGs clustered only with Kulunda MAGs (Supplementary Figures 1-13). As the cultures were inoculated from Cariboo soda lakes, they were likely too rare in these lakes to be detected by Zorz et al. (2019). Two MAGs from Bacteroidota, seven from Gammaproteobacteria, two from Alphaproteobacteria, the only MAG from Patescibacteria, and the Archaea showed less similarity to Cariboo and Kulunda lake MAGs and clustered at either order or class level (Supplementary Figures 1-12). For these 12 MAGs, it is still unknown whether the associated species came from the soda lakes or joined the community during selective enrichment.

To further assess the overall stability of the consortium, we compared relative DNA sequence abundances and proteinaceous biomass contributions of each MAG and estimated the "turnover" of the heterotrophic community across conditions (Supplementary Table 1). Estimates based on relative DNA sequence abundance indicated that approximately $50 \%$ of the heterotrophic community was different among tubular PBR conditions and approximately $80 \%$ of the tubular PBR community was turned over (different) after 1 year in the stirred PBR. Estimates for turnover based on proteinaceous biomass contributions were lower, approximately $25 \%$ between tubular PBR conditions. There is no compelling reason to assign more confidence to protein or DNA based estimates, so the actual community turnover was estimated to be between 25 and 50\% across tubular PBR conditions. Analysis of community turnover at different taxonomic levels (genus, family, order, and class) revealed slightly lower (44 versus 50\% based on DNA, 20 versus $25 \%$ based on protein) turnover at class level, indicating that different taxa sharing the same class might fill in for each other to 
some extent (functional redundancy). Overall, the consortium's heterotrophic community displayed a balance of conservation and dynamics within the context of the tubular PBRs. The shift to stirred PBRs provoked more rampant change within the heterotrophic community.

The gene content of each MAG in the consortium was used to infer whether the consortium's populations fulfilled the six ecological niches postulated in the introduction: (1) harvesting radiation not used by cyanobacteria as supplementary energy source; (2) use of cyanobacterial fermentation products; (3) use of cyanobacterial compatible solutes; (4) use of cyanobacterial storage compounds; (5) use of polysaccharides of the cyanobacterial cell wall; and (6) direct predation of other cells. For each carbon and energy source we looked for genes potentially involved in uptake and transport of the compound as well as for genes encoding biochemical pathways for their conversion. We also considered experimental studies of the phenotypes of related bacteria from the literature. Figure 3 shows the association of consortium's populations with different ecological niches with details provided in Supplementary Table 3 .

The ability to use light energy not used by cyanobacteria (niche 1) was found for half of the heterotrophic members of the consortium. MAG 52 (Oceanicaulis) and MAG 58 (Roseinatronobacter) from Alphaproteobacteria had genes for photosystem I, as well as for biosynthesis of bacteriochlorophyll $a$ (Figure 3 and Supplementary Table 3). These systems are known to harvest wavelengths of light in the near infrared range of 800-850 $\mathrm{nm}$ (Croce and Van Amerongen, 2014). For comparison, cyanobacteria use chlorophylls as well as other antenna pigments to harvest visible light between 495 and $670 \mathrm{~nm}$ (Croce and Van Amerongen, 2014). The aerobic bacteriochlorophyll-containing bacteria perform cyclic electron flow, while translocating protons across the cytoplasmic membrane, powering ATP production (Ke et al., 1970; Kolber et al., 2000). Oceanicaulis alexandrii is closely related to MAG 52 (Supplementary Figure 2) and is known as non-motile rod-shaped aerobic chemoorganoheterotroph (Strömpl et al., 2003). Roseinatronobacter monicus is closely related to MAG 58 (Supplementary Figure 1) and is known as an alkaliphilic aerobic photoorganoheterotroph (Boldareva et al., 2007).

All consortium members affiliated with Bacteroidota, as well as MAG 57 (Wenzhouxiangella), and MAG 56 (Verrucomicrobiota) had genes for light-driven proton pumps known as proteorhodopsins (PRs) (Figure 3 and Supplementary Table 3; McCarren and DeLong, 2007; Pinhassi et al., 2016; Gómez-Consarnau et al., 2019). Phototrophy through proteorhodopsins can provide a considerable amount of energy (Gómez-Consarnau et al., 2007) for ATP synthesis (Steindler et al., 2011), vitamin B1 acquisition

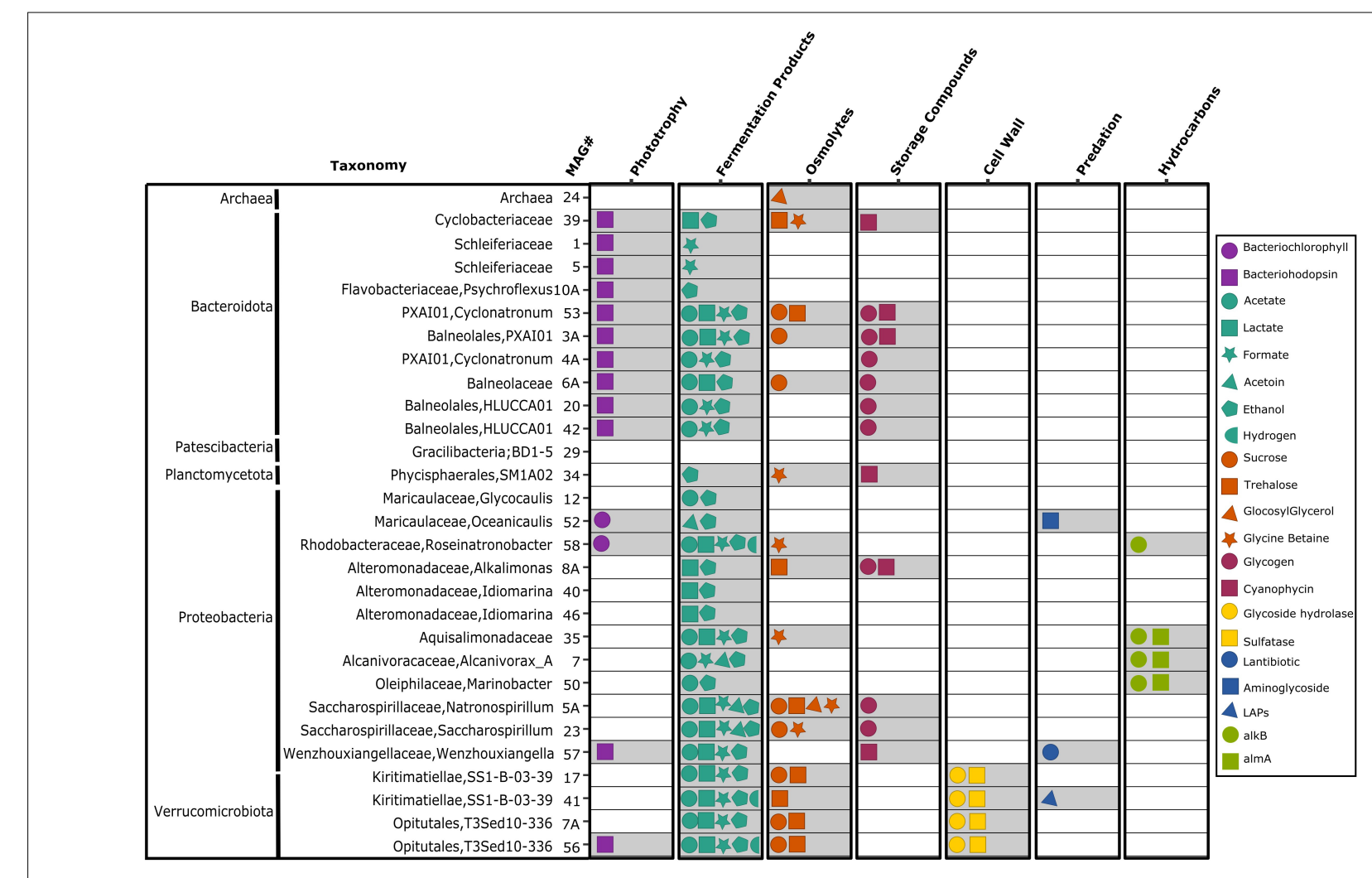

FIGURE 3 | Inference of ecological niches based on gene content. For each MAG, inferred ecological niches are shown, with each symbol indicating a complete set of genes for the associated biochemical pathway. LAPs, linear azol(in)e-containing peptides; alkB, alkane-1-monooxygenase; and almA, flavin-binding monooxygenase. Detailed data in Supplementary Table 3. 
(Gómez-Consarnau et al., 2016), and bacterial survival during starvation (Gómez-Consarnau et al., 2010). Proteorhodopsins were found in various marine and freshwater ecosystems and harvest light at two different wavelengths. The greenabsorbing pigments have a maximum absorption at $520 \mathrm{~nm}$ and the blue-absorbing pigments, typically found in deeper waters, have a peak absorption at $480 \mathrm{~nm}$ (Béjà et al., 2001). Proteorhodopsin so far has been detected in diverse bacterial groups including Alphaproteobacteria (Giovannoni et al., 2005; Moran and Miller, 2007), Gammaproteobacteria (Stingl et al., 2007), Bacteroidetes (Gómez-Consarnau et al., 2007), and Verrucomicrobiota (Martinez-Garcia et al., 2012). Members of the phylum Bacteroidota are known to grow attached to particles. They produce peptidases, receptors, and transporters for high-molecular-weight compounds and are best known for degradation of biopolymers, such as polysaccharides (GómezPereira et al., 2012; Fernández-Gómez et al., 2013). Part of the energy to utilize these compounds could be provided through proteorhodopsins.

With regard to the use of cyanobacterial fermentation products (niche 2), almost all members of the consortium could use at least one of acetate, lactate, formate, acetoin, ethanol, and hydrogen (Figure 3 and Supplementary Table 3). This is in line with the capability of $\mathrm{Ca}$. P. Alkaliphilum to produce all these fermentation products (Ataeian et al., 2021). More than half of the consortium members were capable of using osmolytes (niche 3) such as sucrose, trehalose, glucosylglycerol, and glycine betaine (Figure 3 and Supplementary Table 3). Although $\mathrm{Ca}$. P. Alkaliphilum was shown to be capable of producing many osmolytes, the ability to produce glycine betaine was not detected (Ataeian et al., 2021). However, genes for glycine betaine biosynthesis were detected in consortium members affiliated with Proteobacteria (MAGs 12 and 52) and Verrucomicrobiota (MAGs 7A and 56).

The ability to use storage compounds glycogen or cyanophycin as carbon and nitrogen source was postulated as niche 4. Many bacteria can accumulate an intracellular glycogen which can serve as an energy source during carbon limitation. However, only few bacteria are able to use exogenous glycogen (Abbott et al., 2010). All consortium members affiliated with the order Balneolales as well as three MAGs from Gammaproteobacteria (MAGs 8A, 5A, and 23) encoded the genes for pullulanase (Figure 3 and Supplementary Table 3). This cell surface-anchored debranching exoenzyme facilitates the depolymerization and exogenous utilization of glycogen (Bender and Wallenfels, 1966; Bongaerts et al., 2000; Abbott et al., 2010). Natronospirillum operosum, closely related to MAG $5 \mathrm{~A}$ and MAG 23 has been isolated from decaying biomass of a laboratory culture of cyanobacterium Geitlerinema sp. with obligately alkaliphilic growth ( $\mathrm{pH}$ range 7.3-10.4) (Kevbrin et al., 2020). Growth on various carbohydrates, amino acids and proteinaceous substances has been shown for this species consistent with multiple niches associated with these MAGs. Cyanophycin utilization was detected in six members of the consortium from various phyla, all encoding cyanophycinase.

All four consortium members affiliated with Verrucomicrobiota had 6-38 genes for glycoside hydrolysis and
12-37 genes encoding sulfatases (Figure 3 and Supplementary Table 3). This indicated that they may use sulfated glycopolymers as their carbon and energy source (niche 5). Genome sequencing studies showed that a large number of sulfatase genes is one of the features of the Planctomycetes-Verrucomicrobia-Chlamydia (PVC) superphylum (Thrash et al., 2010; Wegner et al., 2013; Spring et al., 2016). Growth experiments on various sulfated polysaccharides followed by gene expression profiles of a marine Planctomycete showed that sulfatases are required for degradation and subsequent utilization of sulfated glycopolymers as a source of carbon (Glöckner et al., 2003; Wegner et al., 2013). Many cyanobacteria have been shown to produce sulfated exopolysaccharides, with many species containing thick capsules surrounding the cells (Vincenzini et al., 1990; De Philippis et al., 1998). Recently, genomic and proteomic analysis of a Verrucomicrobiota bacterium showed that this species specializes in consumption of sulfated polysaccharides containing methyl pentoses during spring algal blooms in the North Sea (Orellana et al., 2021). These findings show that PVC members are likely capable of consumption of sulfated glycopolymers using glycoside hydrolases and sulfatases. Lack of genes for biogenesis of a pilus or flagellum in the Verrucomicrobiota members of the consortium suggested a non-motile lifestyle. This could indicate their possible attachment to the cyanobacterial cell walls or sheath, while feeding on sulfated glycopolymers.

Direct predation of other cells (niche 6) was investigated by a comprehensive search for gene clusters encoding antimicrobial functions. AntiSMASH identified three consortium members, MAG 57 (Wenzhouxiangella), MAG 52 (Oceanicaulis), and MAG 41 (Kiritimatiellae), to be possible predators (Figure 3). The Wenzhouxiangella MAG contains a gene cluster encoding lantibiotic biosynthesis proteins, as was also found previously in a related species isolated from alkaline soda lakes in the Kulunda Steppe (Sorokin et al., 2020). Lantibiotics are post-translationally modified antimicrobial peptides causing cell death, possibly by disturbing the cytoplasmic membrane (van Kraaij et al., 1999). This could lead to the partial disintegration of the target cells. MAG 52 contained core biosynthetic genes for aminoglycoside biosynthesis. Aminoglycosides are bactericidal antibiotics previously shown to target aerobic, gram negative bacteria. They function by creating fissures in the outer membrane of the cell and inhibit protein synthesis through binding to ribosomes (Hancock, 1981; Mingeot-Leclercq et al., 1999). Core biosynthetic genes for another group of posttranslationally modified peptides, linear azol(in)e-containing peptides (LAPs), were detected in one of the two consortium members affiliated with Kiritimatiellae. LAPs have different antibacterial activities, such as disturbing the cell envelope (Molohon et al., 2016) or inhibiting ribosomal function (Metelev et al., 2017).

It remains unknown which cells are targeted by the predators. Given that MAG57 and MAG41 were among the most abundant heterotrophs, the cyanobacterium itself might be a possible target. However, 4 years of crash-free, productive growth indicated that if the cyanobacterium was targeted, some factor must have limited the effectiveness of these predators. Alternatively, the presence of predatory consortium members may create an 
additional barrier to successful colonization by invaders, in addition to resource depletion. Invading microbes might lack resistance to these antimicrobials, because of the lack of prior exposure. For example, Pseudoalteromonas tunicata resides on the surface of the marine alga Ulva lactuca and the tunicate Ciona intestinalis and produces a range of antifouling metabolites, protecting its host. Antibacterial proteins (James et al., 1996), anti-larval molecules (Maki et al., 1988), antialgal peptides (Egan et al., 2001), antifungal tambjamine molecules (Franks et al., 2006), and violacein (Matz et al., 2008) are some of the targeted chemical defense mechanisms used by P. tunicata.

The presence of bacteria related to well-known hydrocarbon degrading species such as Alcanivorax (MAG 7) and Marinobacter (MAG 50) brought up the possibility of hydrocarbon degradation as an unforeseen niche, defined $a$ posteriori (niche 7). Some cyanobacteria are known to co-exist with hydrocarbon degrading bacteria such as Alcanivorax and Marinobacter (Green et al., 2004, 2015; Yakimov et al., 2007; McGenity et al., 2012). In the absence of hydrocarbons, Alcanivorax can still grow with substrates such as pyruvate and succinate (Fernández-Martínez et al., 2003; Naether et al., 2013). However, in our consortia, they would likely be outcompeted by other heterotrophic bacteria. Alcanivorax spp. has been shown to use alkanes released by marine cyanobacteria (Coates et al., 2014; Lea-Smith et al., 2015) and other hydrocarbon-producing eukaryotic algae (Sorigué et al., 2016) using alkane-1-monooxygenase (alkB) and flavinbinding monooxygenase $(\operatorname{alm} A)$. Two marine cyanobacteria, Prochlorococcus and Synechococcus, produce and accumulate C15 and C17 alkanes through two separate pathways (Schirmer et al., 2010; Mendez-Perez et al., 2011; Lea-Smith et al., 2015). One pathway comprises a two-step conversion of fatty acids to fatty aldehydes and then alkanes using fatty acyl ACP reductase (FAAR) and aldehyde deformylating oxygenase (ADO). The second involves elongating the acyl chain by a polyketide synthase (PKS) followed by decarboxylation to produce a terminal alkene. Ca. P. alkaliphilum synthesizes long chain alk(a/e)nes using FAAR and ADO through the first pathway. Protein expression for FAAR and ADO has been shown in Ataeian et al. (2021). The ability to degrade hydrocarbons produced by $\mathrm{Ca}$. P. alkaliphilum was assessed in the heterotrophic members of the consortium. The genes alkB and $\operatorname{alm} A$ were detected in both MAG 7 (Alcanivorax) and MAG 50 (Marinobacter) as well as in MAG 35 (Aquisalimonadaceae) and MAG 58 (Roseinatronobacter) (Figure 3). Thus, use of hydrocarbons was discovered as a seventh niche supported in this cyanobacterial consortium.

Although we did not define $\mathrm{CO}_{2}$ fixation as a possible niche for heterotrophs, genes for inorganic carbon fixation were detected within MAG 35 (Aquisalimonadaceae). All of the genes involved in the Calvin-Benson Cycle (CBC), including both subunits of form I ribulose 1,5-bisphosphate carboxylase (RuBisCO), were identified (Supplementary Table 3). Genes encoding a nitrate reductase complex indicate this organism might be a facultative nitrite oxidizer. Alternatively, this bacterium might use the $\mathrm{CBC}$ cycle as a sink for reducing equivalents produced during heterotrophic metabolism. This bacterium was otherwise assigned to use of fermentation products, osmolytes, and storage compounds.

Most heterotrophic populations of the consortium were found to occupy multiple ecological niches, and most niches were filled by more than one consortium member, demonstrating functional redundancy among species. None of the discussed niches could be detected in Gracilibacteria, Patescibacteria, the only species affiliated with Candidate Phyla Radiation, MAG 29. Genomic analysis of the members of this phylum has shown that they have limited metabolism sometimes lacking glycolysis, the pentose phosphate and Entner-Doudoroff pathways. They likely live a symbiont or endosymbiont lifestyle (Sieber et al., 2019). They have been shown to acquire pyruvate, acetyl coenzyme A (acetylCoA), and oxaloacetate through degradation of externally derived citrate, malate, and amino acids (Sieber et al., 2019). Given its low abundance, it remains unknown which other consortium member functions as its partner or host.

The one Archaea, affiliated with Nanoarchaeia (Nanoarchaeota phylum, MAG 24), in the consortium, contained genes only for glucosylglycerol degradation among the seven niches (Figure 3). The only representative from this phylum, Nanoarchaeum equitans, was shown to be an obligate symbiont, lacking genes for lipid, cofactor, amino acid, or nucleotide biosynthesis, but encodes genes for information processing and repair (Waters et al., 2003; Castelle et al., 2018).

\section{Stable Isotope Probing/Proteomics Shows Uptake of Carbon Sources by Community Members During Day and Night}

To determine the carbon transfer dynamics in the consortium we used high-throughput stable isotope probing with ${ }^{13} \mathrm{C}$-labeled bicarbonate, followed by proteomics (protein/SIP). This way, we determined the ${ }^{13} \mathrm{C} /{ }^{12} \mathrm{C}$ ratio for individual populations based on the ${ }^{13} \mathrm{C}$ content of their peptides. Experiments were carried out over 2 day/night cycles. The analytical error in the protein/SIP results is mainly determined by the number of peptides analyzed. Because most heterotrophs were relatively rare and yielded only few peptides for analysis, the estimates for their ${ }^{13} \mathrm{C}$ content often remained quite rough. This made quantitative interpretation of dynamics difficult.

The box and whisker plots and trends presented in Figure 4 shows uptake of ${ }^{13} \mathrm{C}$ by $\mathrm{Ca}$. P. alkaliphilum and, potentially, transfer to the heterotrophic populations. $\mathrm{Ca}$. P. alkaliphilum showed the highest number of peptides with measurable ${ }^{13} \mathrm{C}$ content $(n=27,222)$. The aggregated heterotrophic signal was dominated by two heterotrophs that were most abundant in this experiment: MAG 34 Phycisphaerales (MAG 34) and Wenzhouxiangella (MAG 57). The five heterotrophs detected in lower abundance ( $<40$ peptides) Opitutales (MAGs 56 and 7A), Rhodobacteraceae (MAG 58), Kiritimatiellae (MAGs 17 and 41), Saccharospirillum (MAGs 23 and 5A), and Aquisalimonadaceae (MAG 35), do show evidence for ${ }^{13} \mathrm{C}$ uptake, but the dynamics were hard to interpret. These populations were all still among the most abundant heterotrophs at high-pH (Figure 2 and Supplementary Table 1). 


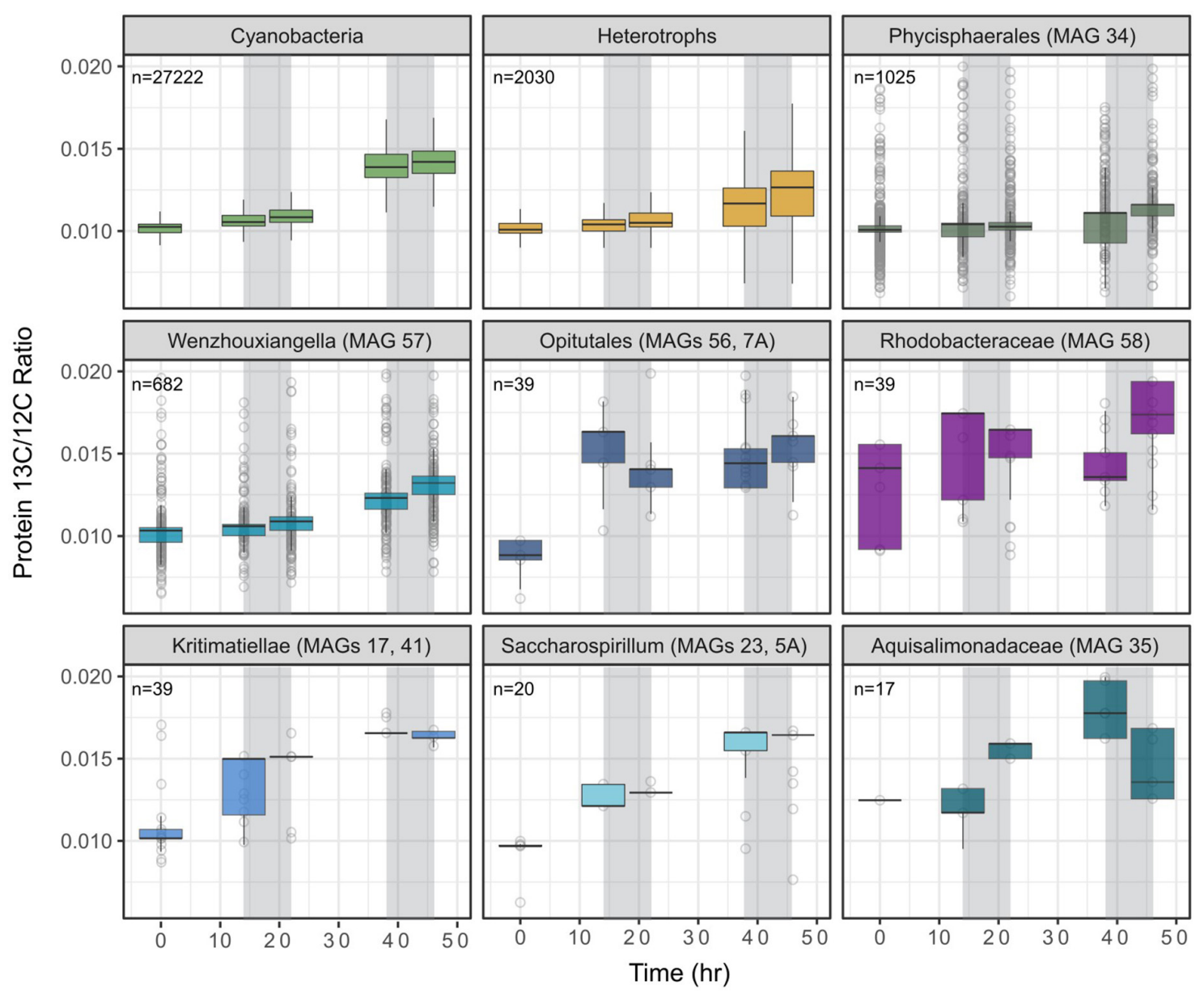

FIGURE 4 | Carbon flow from Candidatus "Phormidium alkaliphilum" (Cyanobacteria) to the consortium's heterotrophs, assessed by SIP/Proteomics. The culture was incubated with $2 \%{ }^{13} \mathrm{C}$ for 4 days. Gray shadings indicate the $8 \mathrm{~h}$ dark periods. Box plots show weighted mean ${ }^{13} \mathrm{C} /{ }^{12} \mathrm{C}$ ratio (middle bar) and 25 and $75 \%$ confidence intervals. Individual peptide ratios and number of peptides assigned are indicated. Supplementary Table 4 provides summary statistics.

During day 1 and night 1 , the median ${ }^{13} \mathrm{C} /{ }^{12} \mathrm{C}$ ratio of Ca. P. alkaliphilum showed only a modest increase (Figure 4 and Supplementary Table 4). During day 2, the rate of ${ }^{13} \mathrm{C}$ assimilation into protein by $\mathrm{Ca}$. P. alkaliphilum peaked, and the ${ }^{13} \mathrm{C} /{ }^{12} \mathrm{C}$ ratio increased by $3.0 \times 10^{-3}$ over $16 \mathrm{~h}$. The second night showed a slower increase at $0.2 \times 10^{-3}$ over $8 \mathrm{~h}$. The lower incorporation at night time compared to day time may indicate $\mathrm{Ca}$. P. alkaliphilum mainly performs protein synthesis during day time, as previously observed (Singer and Doolittle, 1975; Hood et al., 2016). Additionally, the differences between the rate of ${ }^{13} \mathrm{C} /{ }^{12} \mathrm{C}$ increase during day 1 and day 2 suggest that $\mathrm{C}$ incorporation into cyanobacterial proteins is a two-step process: the newly fixed carbon first accumulates in an intermediate glycogen pool before being assimilated into proteins (Polerecky et al., 2021; Rabouille et al., 2021). Such an intermediate glycogen pool would initially consist mainly of ${ }^{12} \mathrm{C}$, as it was synthesized before the addition of ${ }^{13} \mathrm{C}$-bicarbonate. Our data indicate that ${ }^{13} \mathrm{C}$ bicarbonate makes its way via the glycogen pool into the $\mathrm{Ca}$. P. alkaliphilum protein pool on the timescale of a day.
The bulk heterotrophic ${ }^{13} \mathrm{C} /{ }^{12} \mathrm{C}$ ratio generally follows the same pattern as $\mathrm{Ca}$. P. alkaliphilum, with the largest increase in ${ }^{13} \mathrm{C} /{ }^{12} \mathrm{C}$ on day 2 , and more incremental increases at other timepoints. This is consistent with the assumed transfer of carbon from $\mathrm{Ca}$. P. alkaliphilum to heterotrophic populations. Metabolic niche analysis indicated several possible mechanisms of uptake of fixed organic carbon, summarized in Figure 3. For the two most abundant heterotrophs, affiliated with Phycisphaerales (MAG 34) and Wenzhouxiangella (MAG 57), the increase in ${ }^{13} \mathrm{C} /{ }^{12} \mathrm{C}$ of their proteins lagged behind the increase observed for $\mathrm{Ca}$. P. alkaliphilum, suggesting that these two heterotrophic populations derived their protein from Ca. P. alkaliphilum macromolecules (e.g., protein, glycogen). For the other heterotrophs shown in Figure $4,{ }^{13} \mathrm{C}$ uptake appeared to precede cyanobacterial uptake, suggesting that these populations derived their ${ }^{13} \mathrm{C}$-labeled proteins directly from Ca. P. alkaliphilum metabolites rather than ${ }^{13} \mathrm{C}$-labeled $\mathrm{Ca}$. P. alkaliphilum protein. Cyanobacteria can release these so-called "leaky-metabolites," such as pyruvate and 2-oxoglutarate, because high rates of carbon fixation can overwhelm their biosynthetic 
pathways (Cano et al., 2018). For example, cyanobacteria in marine surface waters release each day the same series of metabolites, which are subsequently assimilated or metabolized by heterotrophic bacteria (Aylward et al., 2015). Whether a similar trophic cascade occurred also in our PBR systems cannot be ascertained from the present data.

\section{Similar Cyanobacteria and Similar Consortia}

At an average nucleotide identity (ANI) of $86.3 \%$, Phormidium OSCR (GCA_001314905.1) (Nelson et al., 2016) is closely related to Ca. P. alkaliphilum (Ataeian et al., 2021). A functionally stable cyanobacterial consortium containing Phormidium OSCR was previously enriched from microbial mats in Hot Lake (Cole et al., 2014). The P. OSCR culture grows at Hot Lake conditions that include high concentrations of magnesium sulfate (400 mM). We used the GTDBtk to investigate the similarities between the $\mathrm{Ca}$. P. alkaliphilum and P. OSCR consortia. Despite differences in medium composition, salinity, $\mathrm{pH}$, and alkalinity of the systems (Supplementary Table 5), the two consortia exhibited fairly similar community structure. Both contained many heterotrophic populations even though no exogenous organic carbon source was provided. A total of 12/18 MAGs from $P$. OSCR consortium clustered together with 9 MAGs from $\mathrm{Ca}$. P. alkaliphilum consortium at the family or genus level (Figure 2, Supplementary Table 2, and Supplementary Figures 1-13). The shared heterotrophic populations were MAG numbers 39, 20,42,52,58,8A, 40, 46, and 50 assigned to Alphaproteobacteria, Gammaproteobacteria, and Bacteroidota. This suggests $C a$. P. alkaliphilum and P. OSCR support similar ecological niches. The shared heterotrophs occupy all the discussed niches except for utilization of sulfated glycopolymers of the cell wall. Probably, this niche was occupied by very different species in these two consortia.

\section{Potential Productivity Losses Associated With Heterotrophs}

Growth of cyanobacterial photoautotrophs drives biomass production. This organic carbon supports growth of heterotrophic bacteria. The increase in the ${ }^{13} \mathrm{C} /{ }^{12} \mathrm{C}$ ratio of heterotrophic bacteria suggested transfer of carbon from cyanobacteria to heterotrophs and provided experimental support for this notion. As the aim of cyanobacterial biotechnology is to produce cyanobacteria, heterotrophic growth may be undesirable from a productivity perspective. For example, when growing cyanobacteria to produce phycocyanin, a valuable proteinaceous blue pigment, the presence of heterotrophs may reduce the overall phycocyanin yield.

In our consortium, the relative abundance of heterotrophs was $17 \pm 7 \%$, as estimated based on the combined metagenome, proteome, and phyloFlash data (Supplementary Table 1). Aerobic heterotrophs respire up to one additional carbon atom for every carbon atom they assimilate (Roller and Schmidt, 2015). Assuming that the relative abundance is a good estimator for the relative amount of biomass, the net cyanobacterial biomass production of $\sim 83 \mathrm{~g}$ is a result of the gross cyanobacterial biomass production of $\sim 117 \mathrm{~g}$ combined with a loss of $\sim 34 \mathrm{~g}$ of cyanobacterial biomass due to the growth of heterotrophs ( $\sim 17 \mathrm{~g}$ each for the heterotrophic anabolism and catabolism). Thus, the efficiency of the total biomass production in the consortium was about $85 \%(100 / 117)$ and the efficiency of the cyanobacterial biomass production was about $70 \%(83 / 117)$. For comparison, the overall energy conversion efficiency. For comparison, the overall energy conversion efficiency (from incident sunlight to biomass produced) of natural photosynthetic systems such as microbial mats or man-made algae cultivation systems ranges between 1 and 7\% (Al-Najjar et al., 2010, 2012; Ooms et al., 2016; Zorz et al., 2021). The overall efficiency is low because of many factors, including reflection of light from the photobioreactor or water surface, partial utilization of the available light spectrum, light absorption by photosynthetically inactive molecules or particles, a relatively low maximum turnover rate of photosystems, losses during energy conservation and $\mathrm{CO}_{2}$ fixation ("dark") reactions, and cell maintenance processes. Thus, losses associated with the conversion of light energy into the production of heterotrophic biomass are relatively minor. Also, it is unclear whether cyanobacterial pure cultures are able to convert all the produced carbon into useful biomass. Overflow of fermentation products (Cano et al., 2018), release of osmolytes (Hagemann, 2011), and remains of dead cells (Aguilera et al., 2021) are examples of organic carbon produced by cyanobacteria that may remain unused even in the absence of heterotrophs.

Heterotrophic members of the consortium were assigned to seven ecological niches: phototrophy, use of fermentation products, compatible solutes, storage compounds, polysaccharides of the cyanobacterial cell wall, direct predation, and hydrocarbons. Most niches were filled by more than one consortium member, demonstrating functional redundancy among heterotrophs. Occupation of heterotroph niches, along with redundancy within niches may explain the apparent ecological robustness of the consortium, which is evident from 4 years of crash-free growth in open laboratory culture, as well as the seamless adaptation to different culture conditions. The similar community structure of a consortium of a closely related cyanobacterium supported the occurrence of the same suite of ecological niches.

\section{DATA AVAILABILITY STATEMENT}

The datasets presented in this study can be found in online repositories. The names of the repository/repositories and accession number(s) can be found below: https: //www.ncbi.nlm.nih.gov/, BioProject PRJNA377096, Biosamples SAMN21419665-93, SAMN17969417-20, and SAMN18025958-60; https://www.ebi.ac.uk/pride/archive/, PXD024393, PXD028578.

\section{AUTHOR CONTRIBUTIONS}

MA performed metagenome sequencing, data analysis as well as proteomics and data processing, and drafted the manuscript. YL, 
$\mathrm{AK}$, and $\mathrm{AH}$ performed protein/SIP experiments and analyzed and interpreted the data. MS and $\mathrm{AH}$ reviewed and edited the manuscript. All authors approved the submitted version.

\section{FUNDING}

This study was supported by the Natural Sciences and Engineering Research Council (NSERC), Canada Foundation for Innovation (CFI), Canada First Research Excellence Fund (CFREF), Alberta Innovates, the Government of Alberta, the University of Calgary.

\section{REFERENCES}

Abbott, D. W., Higgins, M. A., Hyrnuik, S., Pluvinage, B., Lammerts van Bueren, A., and Boraston, A. B. (2010). The molecular basis of glycogen breakdown and transport in Streptococcus pneumoniae. Mol. Microbiol. 77, 183-199. doi: 10.1111/j.1365-2958.2010.07199.x

Aguilera, A., Klemenčič, M., Sueldo, D. J., Rzymski, P., Giannuzzi, L., and Martin, M. V. (2021). Cell Death in Cyanobacteria: current Understanding and Recommendations for a Consensus on Its Nomenclature. Front. Microbiol. 12:631654. doi: 10.3389/fmicb.2021.631654

Aharonovich, D., and Sher, D. (2016). Transcriptional response of Prochlorococcus to co-culture with a marine Alteromonas: differences between strains and the involvement of putative infochemicals. ISME J. 10, 2892-2906. doi: 10.1038/ ismej.2016.70

Al-Najjar, M. A. A., de Beer, D., Jørgensen, B. B., Kühl, M., and Polerecky, L. (2010). Conversion and conservation of light energy in a photosynthetic microbial mat ecosystem. ISME J. 4, 440-449. doi: 10.1038/ismej.2009.121

Al-Najjar, M. A. A., de Beer, D., Kühl, M., and Polerecky, L. (2012). Light utilization efficiency in photosynthetic microbial mats. Environ. Microbiol. 14, 982-992. doi: 10.1111/j.1462-2920.2011.02676.x

Amin, S., Hmelo, L., Van Tol, H., Durham, B., Carlson, L., Heal, K. R., et al. (2015). Interaction and signalling between a cosmopolitan phytoplankton and associated bacteria. Nature 522, 98-101. doi: 10.1038/nature14488

Amin, S. A., Green, D. H., Hart, M. C., Küpper, F. C., Sunda, W. G., and Carrano, C. J. (2009). Photolysis of iron-siderophore chelates promotes bacterial-algal mutualism. Proc. Natl. Acad. Sci. U. S. A. 106, 17071-17076. doi: 10.1073/pnas. 0905512106

Ataeian, M., Liu, Y., Canon-Rubio, K. A., Nightingale, M., Strous, M., and Vadlamani, A. (2019). Direct capture and conversion of CO2 from air by growing a cyanobacterial consortium at $\mathrm{pH}$ up to 11.2. Biotechnol. Bioeng. 116, 1604-1611. doi: 10.1002/bit.26974

Ataeian, M., Vadlamani, A., Haines, M., Mosier, D., and Dong, X. (2021). Proteome and strain analysis of cyanobacterium Candidatus "Phormidium alkaliphilum" reveals traits for success in biotechnology. Iscience 24:103405. doi: 10.1016/j.isci. 2021.103405

Aylward, F. O., Eppley, J. M., Smith, J. M., Chavez, F. P., Scholin, C. A., and DeLong, E. F. (2015). Microbial community transcriptional networks are conserved in three domains at ocean basin scales. Proc. Natl. Acad. Sci. 112, 5443-5448. doi: 10.1073/pnas.1502883112

Azam, F. (1998). Microbial control of oceanic carbon flux: the plot thickens. Science 280, 694-696.

Azam, F., and Malfatti, F. (2007). Microbial structuring of marine ecosystems. Nat. Rev Microbiol. 5, 782-791. doi: 10.1038/nrmicro 1747

Béjà, O., Spudich, E. N., Spudich, J. L., Leclerc, M., and DeLong, E. F. (2001). Proteorhodopsin phototrophy in the ocean. Nature 411, 786-789. doi: 10.1038/ 35081051

Beliaev, A. S., Romine, M. F., Serres, M., Bernstein, H. C., and Linggi, B. E. (2014). Inference of interactions in cyanobacterial-heterotrophic co-cultures via transcriptome sequencing. ISME J. 8, 2243-2255. doi: 10.1038/ismej.20 14.69

Ben Hania, W., Joseph, M., Bunk, B., Spröer, C., Klenk, H.-P., Fardeau, M. L., et al. (2017). Characterization of the first cultured representative of a Bacteroidetes

\section{ACKNOWLEDGMENTS}

We thank Dan Liu for laboratory support. We also would like to thank Srijak Bhatnagar, Xiaoli Dong, and Muhe Diao for help with metagenome analysis.

\section{SUPPLEMENTARY MATERIAL}

The Supplementary Material for this article can be found online at: https://www.frontiersin.org/articles/10.3389/fmicb. 2022.780346/full\#supplementary-material

clade specialized on the scavenging of cyanobacteria. Environ. Microbiol. 19, 1134-1148. doi: 10.1111/1462-2920.13639

Bender, H., and Wallenfels, K. (1966). [95] Pullulanase (an amylopectin and glycogen debranching enzyme) from Aerobacter aerogenes. Methods Enzymol. 8, 555-559. doi: 10.1016/0076-6879(66)08100-x

Biller, S. J., Coe, A., and Chisholm, S. W. (2016). Torn apart and reunited: impact of a heterotroph on the transcriptome of Prochlorococcus. ISME J. 10, 2831-2843. doi: 10.1038/ismej.2016.82

Biller, S. J., Schubotz, F., Roggensack, S. E., Thompson, A. W., Summons, R. E., and Chisholm, S. W. (2014). Bacterial vesicles in marine ecosystems. Science 343, 183-186. doi: 10.1126/science. 1243457

Blin, K., Shaw, S., Steinke, K., Villebro, R., Ziemert, N., Lee, S. Y., et al. (2019). antiSMASH 5.0: updates to the secondary metabolite genome mining pipeline. Nucleic Acids Res. 47, W81-W87. doi: 10.1093/nar/gkz310

Boldareva, E. N., Bryantseva, I. A., Tsapin, A., Nelson, K., Sorokin, D. Y., Turova, T. P., et al. (2007). The new alkaliphilic bacteriochlorophyll a-containing bacterium Roseinatronobacter monicus sp. nov. from the hypersaline Soda Mono Lake (California, United States). Microbiology 76, 82-92. doi: 10.1134/ s0026261707010122

Bongaerts, R. J., Heinz, H.-P., Hadding, U., and Zysk, G. (2000). Antigenicity, expression, and molecular characterization of surface-located pullulanase of Streptococcus pneumoniae. Infect. Immun. 68, 7141-7143. doi: 10.1128/IAI.68. 12.7141-7143.2000

Brady, A. L., Druschel, G., Leoni, L., Lim, D. S., and Slater, G. F. (2013). Isotopic biosignatures in carbonate-rich, cyanobacteria-dominated microbial mats of the Cariboo Plateau, B.C. Geobiology 11, 437-456. doi: 10.1111/gbi. 12050

Brockhurst, M. A., Colegrave, N., Hodgson, D. J., and Buckling, A. (2007). Niche occupation limits adaptive radiation in experimental microcosms. PLoS One 2:e193. doi: 10.1371/journal.pone.0000193

Cano, M., Holland, S. C., Artier, J., Burnap, R. L., and Ghirardi, M. (2018). Glycogen Synthesis and Metabolite Overflow Contribute to Energy Balancing in Cyanobacteria. Cell Rep. 23, 667-672. doi: 10.1016/j.celrep.2018.03.083

Castelle, C. J., Brown, C. T., Anantharaman, K., Probst, A. J., Huang, R. H., and Banfield, J. F. (2018). Biosynthetic capacity, metabolic variety and unusual biology in the CPR and DPANN radiations. Nat. Rev. Microbiol. 16, 629-645. doi: 10.1038/s41579-018-0076-2

Christie-Oleza, J. A., Scanlan, D. J., and Armengaud, J. (2015). "You produce while I clean up", a strategy revealed by exoproteomics during SynechococcusRoseobacter interactions. Proteomics 15, 3454-3462. doi: 10.1002/pmic. 201400562

Christie-Oleza, J. A., Sousoni, D., Lloyd, M., Armengaud, J., and Scanlan, D. J. (2017). Nutrient recycling facilitates long-term stability of marine microbial phototroph-heterotroph interactions. Nat. Microbiol. 2:17100. doi: 10.1038/ nmicrobiol.2017.100

Coates, R. C., Podell, S., Korobeynikov, A., Lapidus, A., Pevzner, P., Sherman, D. H., et al. (2014). Characterization of Cyanobacterial Hydrocarbon Composition and Distribution of Biosynthetic Pathways. PLoS One 9:e85140. doi: 10.1371/ journal.pone. 0085140

Cole, J. K., Hutchison, J. R., Renslow, R. S., Kim, Y. M., Chrisler, W. B., Engelmann, H. E., et al. (2014). Phototrophic biofilm assembly in microbialmat-derived unicyanobacterial consortia: model systems for the study of 
autotroph-heterotroph interactions. Front. Microbiol. 5:109. doi: 10.3389/fmicb. 2014.00109

Costa, K. C., Navarro, J. B., Shock, E. L., Zhang, C. L., Soukup, D., and Hedlund, B. P. (2009). Microbiology and geochemistry of great boiling and mud hot springs in the United States Great Basin. Extremophiles 13, 447-459. doi: 10. 1007/s00792-009-0230-x

Croce, R., and Van Amerongen, H. (2014). Natural strategies for photosynthetic light harvesting. Nat. Chem. Biol. 10, 492-501.

Croft, M. T., Lawrence, A. D., Raux-Deery, E., Warren, M. J., and Smith, A. G. (2005). Algae acquire vitamin B 12 through a symbiotic relationship with bacteria. Nature 438, 90-93. doi: 10.1038/nature 04056

Croft, M. T., Warren, M. J., and Smith, A. G. (2006). Algae need their vitamins. Eukaryot. Cell 5, 1175-1183. doi: 10.1128/EC.00097-06

De Philippis, R., Margheri, M. C., Materassi, R., and Vincenzini, M. (1998). Potential of unicellular cyanobacteria from saline environments as exopolysaccharide producers. Appl. Environ. Microbiol. 64, 1130-1132. doi: 10.1128/AEM.64.3.1130-1132.1998

Dong, X., and Strous, M. (2019). An integrated pipeline for annotation and visualization of metagenomic contigs. Front. Genet. 10:999. doi: 10.3389/fgene. 2019.00999

D’Onofrio, A., Crawford, J. M., Stewart, E. J., Witt, K., and Gavrish, E. (2010). Siderophores from neighboring organisms promote the growth of uncultured bacteria. Chem. Biol. 17, 254-264. doi: 10.1016/j.chembiol.2010.02.010

Duffy, J. E., Godwin, C. M., and Cardinale, B. J. (2017). Biodiversity effects in the wild are common and as strong as key drivers of productivity. Nature 549, 261-264. doi: 10.1038/nature23886

Egan, S., James, S., Holmström, C., and Kjelleberg, S. (2001). Inhibition of algal spore germination by the marine bacterium Pseudoalteromonas tunicata. FEMS Microbiol. Ecol. 35, 67-73. doi: 10.1111/j.1574-6941.2001.tb00789.x

Falkowski, P. G., Barber, R. T., and Smetacek, V. (1998). Biogeochemical controls and feedbacks on ocean primary production. Science 281, 200-206. doi: 10. $1126 /$ science.281.5374.200

Fernández-Gómez, B., Richter, M., Schüler, M., Pinhassi, J., Acinas, S. G., González, J. M., et al. (2013). Ecology of marine Bacteroidetes: a comparative genomics approach. ISME J. 7, 1026-1037. doi: 10.1038/ismej.2012.169

Fernández-Martínez, J., Pujalte, M. J., García-Martínez, J., Mata, M., Garay, E., and Rodríguez-Valera, F. (2003). Description of Alcanivorax venustensis sp. nov. and reclassification of Fundibacter jadensis DSM 12178T (Bruns and BertheCorti 1999) as Alcanivorax jadensis comb. nov., members of the emended genus Alcanivorax. Int. J. Syst. Evol. Microbiol. 53, 331-338. doi: 10.1099/ijs.0.01923-0

Florens, L., Carozza, M. J., Swanson, S. K., Fournier, M., Coleman, M. K., Workman, J. L., et al. (2006). Analyzing chromatin remodeling complexes using shotgun proteomics and normalized spectral abundance factors. Methods 40, 303-311. doi: 10.1016/j.ymeth.2006.07.028

Foissner, W. (2012). Schmidingerothrix extraordinaria nov. gen., nov. spec., a secondarily oligomerized hypotrich (Ciliophora, Hypotricha, Schmidingerotrichidae nov. fam.) from hypersaline soils of Africa. Eur. J. Protistol. 48, 237-251. doi: 10.1016/j.ejop.2011.11.003

Forehead, H. I., and O'Kelly, C. J. (2013). Small doses, big troubles: modeling growth dynamics of organisms affecting microalgal production cultures in closed photobioreactors. Bioresour. Technol. 129, 329-334. doi: 10.1016/j. biortech.2012.11.082

Franks, A., Egan, S., Holmström, C., James, S., Lappin-Scott, H., and Kjelleberg, S. (2006). Inhibition of fungal colonization by Pseudoalteromonas tunicata provides a competitive advantage during surface colonization. Appl. Environ. Microbiol. 72, 6079-6087. doi: 10.1128/AEM.00559-06

Gallien, L., and Carboni, M. (2017). The community ecology of invasive species: where are we and what's next?. Ecography 40, 335-352. doi: 10.1111/ ecog.02446

Giovannoni, S. J., Tripp, H. J., Givan, S., Podar, M., and Vergin, K. L. (2005). Genome streamlining in a cosmopolitan oceanic bacterium. Science 309, 12421245. doi: $10.1126 /$ science. 1114057

Glöckner, F. O., Kube, M., Bauer, M., Teeling, H., Lombardot, T., Ludwig, W., et al. (2003). Complete genome sequence of the marine planctomycete Pirellula sp. strain 1. Proc. Natl. Acad. Sci. U.S.A. 100, 8298-8303. doi: 10.1073/pnas. 1431443100

Gómez-Consarnau, L., Akram, N., Lindell, K., Pedersen, A., Neutze, R., Milton, D. L., et al. (2010). Proteorhodopsin phototrophy promotes survival of marine bacteria during starvation. PLoS Biol. 8:e1000358. doi: 10.1371/journal.pbio. 1000358

Gómez-Consarnau, L., González, J. M., Coll-Lladó, M., Gourdon, P., and Pascher, T. (2007). Light stimulates growth of proteorhodopsin-containing marine Flavobacteria. Nature 445, 210-213. doi: 10.1038/nature05381

Gómez-Consarnau, L., González, J. M., Riedel, T., Jaenicke, S., and WagnerDöbler, I. (2016). Proteorhodopsin light-enhanced growth linked to vitamin-B 1 acquisition in marine Flavobacteria. ISME J. 10, 1102-1112. doi: 10.1038/ismej. 2015.196

Gómez-Consarnau, L., Raven, J. A., Levine, N. M., Cutter, L. S., Wang, D., Seegers, B., et al. (2019). Microbial rhodopsins are major contributors to the solar energy captured in the sea. Sci. Adv. 5:eaaw8855. doi: 10.1126/sciadv.aaw8855

Gómez-Pereira, P. R., Schüler, M., Fuchs, B. M., Bennke, C., Teeling, H., Waldmann, J., et al. (2012). Genomic content of uncultured Bacteroidetes from contrasting oceanic provinces in the North Atlantic Ocean. Environ. Microbiol. 14, 52-66. doi: 10.1111/j.1462-2920.2011.02555.x

Grant, M. A., Kazamia, E., Cicuta, P., and Smith, A. G. (2014). Direct exchange of vitamin B 12 is demonstrated by modelling the growth dynamics of algalbacterial cocultures. ISME J. 8, 1418-1427. doi: 10.1038/ismej.2014.9

Green, D. H., Echavarri-Bravo, V., Brennan, D., and Hart, M. C. (2015). Bacterial diversity associated with the coccolithophorid algae Emiliania huxleyi and Coccolithus pelagicus f. braarudii. BioMed Res. Int. 2015:194540. doi: 10.1155/ 2015/194540

Green, D. H., Llewellyn, L. E., Negri, A. P., Blackburn, S. I., and Bolch, C. J. (2004). Phylogenetic and functional diversity of the cultivable bacterial community associated with the paralytic shellfish poisoning dinoflagellate Gymnodinium catenatum. FEMS Microbiol. Ecol. 47, 345-357. doi: 10.1016/S0168-6496(03) 00298-8

Grossart, H. P., Czub, G., and Simon, M. (2006). Algae-bacteria interactions and their effects on aggregation and organic matter flux in the sea. Environ. Microbiol. 8, 1074-1084. doi: 10.1111/j.1462-2920.2006.00999.x

Gruber-Vodicka, H. R., Seah, B. K. B., and Pruesse, E. (2019). phyloFlash Rapid SSU rRNA profiling and targeted assembly from metagenomes. bioRxiv [Preprint]. doi: 10.1101/521922

Hagemann, M. (2011). Molecular biology of cyanobacterial salt acclimation. FEMS Microbiol. Rev. 35, 87-123. doi: 10.1111/j.1574-6976.2010. 00234.x

Hamann, E., Gruber-Vodicka, H., Kleiner, M., Tegetmeyer, H. E., Riedel, D., Littmann, S., et al. (2016). Environmental Breviatea harbour mutualistic Arcobacter epibionts. Nature 534, 254-258. doi: 10.1038/nature18297

Hancock, R. E. (1981). Aminoglycoside uptake and mode of action-with special reference to streptomycin and gentamicin. I. Antagonists and mutants. J. Antimicrob. Chemother. 8, 249-276. doi: 10.1093/jac/8.4.249

Holmström, C., Rittschof, D., and Kjelleberg, S. (1992). Inhibition of settlement by larvae of Balanus amphitrite and Ciona intestinalis by a surface-colonizing marine bacterium. Appl. Environ. Microbiol. 58, 2111-2115. doi: 10.1128/aem. 58.7.2111-2115.1992

Hood, R. D., Higgins, S. A., Flamholz, A., Nichols, R. J., and Savage, D. F. (2016). The stringent response regulates adaptation to darkness in the cyanobacterium Synechococcus elongatus. Proc. Natl. Acad. Sci. U.S.A. 113, E4867-E4876. doi: 10.1073/pnas.1524915113

Hünken, M., Harder, J., and Kirst, G. (2008). Epiphytic bacteria on the Antarctic ice diatom Amphiprora kufferathii Manguin cleave hydrogen peroxide produced during algal photosynthesis. Plant Biol. 10, 519-526. doi: 10.1111/j.1438-8677. 2008.00040.x

Jain, C., Rodriguez, R. L., Phillippy, A. M., Konstantinidis, K. T., and Aluru, S. (2018). High throughput ANI analysis of $90 \mathrm{~K}$ prokaryotic genomes reveals clear species boundaries. Nat. Commun. 9:5114.

James, S. G., Holmström, C., and Kjelleberg, S. (1996). Purification and characterization of a novel antibacterial protein from the marine bacterium D2. Appl. Environ. Microbiol. 62, 2783-2788. doi: 10.1128/aem.62.8.2783-2788. 1996

Jousset, A., Schulz, W., Scheu, S., and Eisenhauer, N. (2011). Intraspecific genotypic richness and relatedness predict the invasibility of microbial communities. ISME J. 5, 1108-1114. doi: 10.1038/ismej.2011.9

Kang, D. D., Froula, J., Egan, R., and Wang, Z. (2015). MetaBAT, an efficient tool for accurately reconstructing single genomes from complex microbial communities. PeerJ 3:e1165. doi: 10.7717/peerj.1165 
Karl, D. M. (2002). Nutrient dynamics in the deep blue sea. Trends Microbiol. 10, 410-418. doi: 10.1016/s0966-842x(02)02430-7

Ke, B., Chaney, T. H., and Reed, D. W. (1970). The electrostatic interaction between the reaction-center bacteriochlorophyll derived from Rhodopseudomonas spheroides and mammalian cytochrome $\mathrm{c}$ and its effect on light-activated electron transport. Biochim. Biophys. Acta Bioenerg. 216, 373-383. doi: 10.1016/ 0005-2728(70)90229-x

Kevbrin, V., Boltyanskaya, Y., Grouzdev, D., Koziaeva, V., Park, M., and Cho, J. C. (2020). Natronospirillum operosum gen. nov., sp. nov., a haloalkaliphilic satellite isolated from decaying biomass of a laboratory culture of cyanobacterium Geitlerinema sp. and proposal of Natronospirillaceae fam. nov., Saccharospirillaceae fam. nov. and Gynuellaceae fam. nov. Int. J. Syst. Evol. Microbiol. 70, 511-521.

Kleiner, M., Kouris, A., Jensen, M., Liu, Y., McCalder, J., and Strous, M. (2021). Ultra-sensitive Protein-SIP to quantify activity and substrate uptake in microbiomes with stable isotopes. bioRxiv [Preprint]. doi: 10.1101/2021.03.29. 437612

Kleiner, M., Thorson, E., Sharp, C. E., Dong, X., Liu, D., Li, C., et al. (2017). Assessing species biomass contributions in microbial communities via metaproteomics. Nat. Commun. 8:1558. doi: 10.1038/s41467-01701544-x

Kolber, Z. S., Van Dover, C. L., Niederman, R. A., and Falkowski, P. G. (2000). Bacterial photosynthesis in surface waters of the open ocean. Nature 407, 177-179. doi: $10.1038 / 35025044$

Lea-Smith, D. J., Biller, S. J., Davey, M. P., Cotton, C. A., and Sepulveda, B. M. P. (2015). Contribution of cyanobacterial alkane production to the ocean hydrocarbon cycle. Proc. Natl. Acad. Sci. U. S. A. 112, 13591-13596. doi: 10. 1073/pnas. 1507274112

Li, D., Luo, R., Liu, C. M., Leung, C. M., Ting, H. F., Sadakane, K., et al. (2016). MEGAHIT v1.0: a fast and scalable metagenome assembler driven by advanced methodologies and community practices. Methods 102, 3-11. doi: 10.1016/j. ymeth.2016.02.020

Li, W., and Godzik, A. (2006). Cd-hit: a fast program for clustering and comparing large sets of protein or nucleotide sequences. Bioinformatics 22, 1658-1659. doi: 10.1093/bioinformatics/btl158

Louca, S., Polz, M. F., Mazel, F., Albright, M. B. N., Huber, J. A., O'Connor, M. I., et al. (2018). Function and functional redundancy in microbial systems. Nat. Ecol. Evol. 2, 936-943. doi: 10.1038/s41559-018-0519-1

Maki, J., Rittschof, D., Costlow, J., and Mitchell, R. (1988). Inhibition of attachment of larval barnacles, Balanus amphitrite, by bacterial surface films. Mar. Biol. 97, 199-206. doi: 10.1007/BF00165910

Martinez-Garcia, M., Swan, B. K., Poulton, N. J., Gomez, M. L., and Masland, D. (2012). High-throughput single-cell sequencing identifies photoheterotrophs and chemoautotrophs in freshwater bacterioplankton. ISME J. 6, 113-123. doi: 10.1038/ismej.2011.84

Matz, C., Webb, J. S., Schupp, P. J., Phang, S. Y., Penesyan, A., Egan, S., et al. (2008). Marine Biofilm Bacteria Evade Eukaryotic Predation by Targeted Chemical Defense. PLoS One 3:e2744. doi: 10.1371/journal.pone.0002744

McCarren, J., Becker, J. W., Repeta, D. J., Shi, Y., Young, C. R., Malmstrom, R. R., et al. (2010). Microbial community transcriptomes reveal microbes and metabolic pathways associated with dissolved organic matter turnover in the sea. Proc. Natl. Acad. Sci. U. S. A. 107, 16420-16427. doi: 10.1073/pnas. 1010732107

McCarren, J., and DeLong, E. F. (2007). Proteorhodopsin photosystem gene clusters exhibit co-evolutionary trends and shared ancestry among diverse marine microbial phyla. Environ. Microbiol. 9, 846-858. doi: 10.1111/j.14622920.2006.01203.x

McGenity, T., Folwell, B., McKew, B., and Sanni, G. (2012). Marine crude-oil biodegradation: a central role for interspecies interactions. Aquat. Biosyst. 16:10. doi: 10.1186/2046-9063-8-10

Mendez-Perez, D., Begemann, M. B., and Pfleger, B. F. (2011). Modular synthaseencoding gene involved in $\alpha$-olefin biosynthesis in Synechococcus sp. strain PCC 7002. Appl. Environ. Microbiol. 77, 4264-4267. doi: 10.1128/AEM.004 $67-11$

Metelev, M., Osterman, I. A., Ghilarov, D., Khabibullina, N. F., and Yakimov, A. (2017). Klebsazolicin inhibits 70S ribosome by obstructing the peptide exit tunnel. Nat. Chem. Biol. 13, 1129-1136. doi: 10.1038/nchembio. 2462
Mingeot-Leclercq, M. P., Glupczynski, Y., and Tulkens, P. M. (1999). Aminoglycosides: activity and resistance. Antimicrob. Agents Chemother. 43, 727-737. doi: 10.1128/AAC.43.4.727

Molohon, K. J., Blair, P. M., Park, S., Doroghazi, J. R., Maxson, T., Hershfield, J. R., et al. (2016). Plantazolicin is an ultranarrow-spectrum antibiotic that targets the Bacillus anthracis membrane. ACS infect. Dis. 2, 207-220. doi: 10.1021/ acsinfecdis. 5 b00115

Moran, M. A., and Miller, W. L. (2007). Resourceful heterotrophs make the most of light in the coastal ocean. Nat. Rev. Microbiol. 5, 792-800. doi: 10.1038/ nrmicro1746

Morris, J. J., Kirkegaard, R., Szul, M. J., Johnson, Z. I., and Zinser, E. R. (2008). Facilitation of robust growth of Prochlorococcus colonies and dilute liquid cultures by "helper" heterotrophic bacteria. Appl. Environ. Microbiol. 74, 4530-4534. doi: 10.1128/AEM.02479-07

Naether, D. J., Slawtschew, S., Stasik, S., Engel, M., Olzog, M., Wick, L. Y., et al. (2013). Adaptation of the hydrocarbonoclastic bacterium Alcanivorax borkumensis SK2 to alkanes and toxic organic compounds: a physiological and transcriptomic approach. Appl. Environ. Microbiol. 79, 4282-4293. doi: 10.1128/AEM.00694-13

Nelson, W. C., Maezato, Y., Wu, Y. W., Romine, M. F., and Lindemann, S. R. (2016). Identification and Resolution of Microdiversity through Metagenomic Sequencing of Parallel Consortia. Appl. Environ. Microbiol. 82, 255-267. doi: 10.1128/AEM.02274-15

Oberg, A. L., and Vitek, O. (2009). Statistical design of quantitative mass spectrometry-based proteomic experiments. J. Proteome Res. 8, 2144-2156. doi: $10.1021 /$ pr8010099

Ooms, M. D., Dinh, C. T., Sargent, E. H., and Sinton, D. (2016). Photon management for augmented photosynthesis. Nat. Commun. 7:12699. doi: 10. 1038/ncomms12699

Orellana, L. H., Francis, T. B., Ferraro, M., Hehemann, J.-H., Fuchs, B. M., and Amann, R. I. (2021). Verrucomicrobiota are specialist consumers of sulfated methyl pentoses during diatom blooms. ISME J. [Online ahead of print] doi: 10.1038/s41396-021-01105-7

Paerl, H. W., and Pinckney, J. L. (1996). A Mini-review of Microbial Consortia: their Roles in Aquatic Production and Biogeochemical Cycling. Microb. Ecol. 31, 225-247. doi: 10.1007/BF00171569

Paerl, H. W., Pinckney, J. L., and Steppe, T. F. (2000). Cyanobacterial-bacterial mat consortia_ examining the functional unit of microbial survival and growth in extreme environments. Environ. Microbiol. 2, 11-26. doi: 10.1046/j.1462-2920. 2000.00071.x

Park, J. S., Cho, B. C., and Simpson, A. G. B. (2006). Halocafeteria seosinensis gen. et sp. nov. (Bicosoecida), a halophilic bacterivorous nanoflagellate isolated from a solar saltern. Extremophiles 10, 493-504. doi: 10.1007/s00792-006-0001$\mathrm{x}$

Parks, D. H., Chuvochina, M., Waite, D. W., Rinke, C., Skarshewski, A., Chaumeil, P. A., et al. (2018). A standardized bacterial taxonomy based on genome phylogeny substantially revises the tree of life. Nat. Biotechnol. 36, 996-1004. doi: $10.1038 /$ nbt. 4229

Parks, D. H., Imelfort, M., Skennerton, C. T., Hugenholtz, P., and Tyson, G. W. (2015). CheckM: assessing the quality of microbial genomes recovered from isolates, single cells, and metagenomes. Genome Res. 25, 1043-1055. doi: 10. 1101/gr.186072.114

Pedler, B. E., Aluwihare, L. I., and Azam, F. (2014). Single bacterial strain capable of significant contribution to carbon cycling in the surface ocean. Proc. Natl. Acad. Sci. U. S. A. 111, 7202-7207. doi: 10.1073/pnas.1401887111

Perez-Riverol, Y., Csordas, A., Bai, J., Bernal-Llinares, M., and Hewapathirana, S. (2019). The PRIDE database and related tools and resources in 2019: improving support for quantification data. Nucleic Acids Res. 47, D442-D450. doi: 10.1093/ nar/gkyl106

Petersen, J. M., Kemper, A., Gruber-Vodicka, H., Cardini, U., van der Geest, M., Kleiner, M., et al. (2016). Chemosynthetic symbionts of marine invertebrate animals are capable of nitrogen fixation. Nat. Microbiol. 2:16195.

Pinhassi, J., DeLong, E. F., Béjà, O., González, J. M., and Pedrós-Alió, C. (2016). Marine bacterial and archaeal ion-pumping rhodopsins: genetic diversity, physiology, and ecology. Microbiol. Mol. Biol. Rev. 80, 929-954. doi: 10.1128/ MMBR.00003-16

Polerecky, L., Masuda, T., Eichner, M., Rabouille, S., Vancová, M., Kienhuis, M. V. M., et al. (2021). Temporal patterns and intra- and inter-cellular variability 
in carbon and nitrogen assimilation by the unicellular cyanobacterium Cyanothece sp. ATCC 51142. Front. Microbiol. 12:620915. doi: 10.3389/fmicb. 2021.620915

Puxty, R. J., Evans, D. J., Millard, A. D., and Scanlan, D. J. (2018). Energy limitation of cyanophage development: implications for marine carbon cycling. ISME J. 12, 1273-1286. doi: 10.1038/s41396-017-0043-3

Quinn, J. C., Yates, T., Douglas, N., Weyer, K., Butler, J., Bradley, T. H., et al. (2012). Nannochloropsis production metrics in a scalable outdoor photobioreactor for commercial applications. Bioresour. Technol. 117, 164-171. doi: 10.1016/j. biortech.2012.04.073

Rabouille, S., Campbell, D. A., Masuda, T., Zavřel, T., Bernát, G., Polerecky, L., et al. (2021). Electron \& biomass dynamics of Cyanothece under interacting nitrogen \& carbon limitations. Front. Microbiol. 12:617802. doi: 10.3389/fmicb. 2021.617802

Reed, R. H., Warr, S. R., Kerby, N. W., and Stewart, W. D. (1986). Osmotic shock-induced release of low molecular weight metabolites from free-living and immobilized cyanobacteria. Enzyme microb. Technol. 8, 101-104.

Roller, B. R., and Schmidt, T. M. (2015). The physiology and ecological implications of efficient growth. ISME J. 9, 1481-1487. doi: 10.1038/ismej.2014.235

Saidi-Mehrabad, A., He, Z., Tamas, I., Sharp, C. E., and Brady, A. L. (2013). Methanotrophic bacteria in oilsands tailings ponds of northern Alberta. ISME J. 7, 908-921. doi: 10.1038/ismej.2012.163

Sañudo-Wilhelmy, S. A., Cutter, L. S., Durazo, R., Smail, E. A., Gómez-Consarnau, L., Webb, E. A., et al. (2012). Multiple B-vitamin depletion in large areas of the coastal ocean. Proc. Natl. Acad. Sci. U. S. A. 109, 14041-14045. doi: 10.1073/ pnas. 1208755109

Serang, O., MacCoss, M. J., and Noble, W. S. (2010). Efficient marginalization to compute protein posterior probabilities from shotgun mass spectrometry data. J. Proteome Res. 9, 5346-5357. doi: 10.1021/pr100594k

Schirmer, A., Rude, M. A., Li, X., Popova, E., and Del Cardayre, S. B. (2010). Microbial biosynthesis of alkanes. Science 329, 559-562.

Sharp, C. E., Urschel, S., Dong, X., Brady, A. L., Slater, G. F., and Strous, M. (2017). Robust, high-productivity phototrophic carbon capture at high $\mathrm{pH}$ and alkalinity using natural microbial communities. Biotechnol. Biofuels 10:84. doi: 10.1186/s13068-017-0769-1

Shelef, G., and Soeder, C. J. (1980). Algae Biomass: Production and Use. Amsterdam: Elsevier.

Shurin, J. B., Abbott, R. L., Deal, M. S., Kwan, G. T., and Litchman, E. (2013). Industrial-strength ecology: trade-offs and opportunities in algal biofuel production. Ecol. Lett. 16, 1393-1404. doi: 10.1111/ele.12176

Sieber, C. M. K., Paul, B. G., Castelle, C. J., Hu, P., Tringe, S. G., Valentine, D. L., et al. (2019). Unusual Metabolism and Hypervariation in the Genome of a Gracilibacterium (BD1-5) from an Oil-Degrading Community. mBio 10, e02128-19. doi: 10.1128/mBio.02128-19

Singer, R. A., and Doolittle, W. F. (1975). Control of gene expression in blue-green algae. Nature 253, 650-651. doi: 10.1038/253650a0

Sorigué, D., Légeret, B., Cuiné, S., Morales, P., and Mirabella, B. (2016). Microalgae synthesize hydrocarbons from long-chain fatty acids via a lightdependent pathway. Plant Physiol. 171, 2393-2405. doi: 10.1104/pp.16. 00462

Sorokin, D. Y., Mosier, D., Zorz, J. K., Dong, X., and Strous, M. (2020). Wenzhouxiangella Strain AB-CW3, a Proteolytic Bacterium From Hypersaline Soda Lakes That Preys on Cells of Gram-Positive Bacteria. Front. Microbiol. 11:597686. doi: 10.3389/fmicb.2020.597686

Spring, S., Bunk, B., Spröer, C., Schumann, P., Rohde, M., Tindall, B. J., et al. (2016). Characterization of the first cultured representative of Verrucomicrobia subdivision 5 indicates the proposal of a novel phylum. ISME J. 10, 2801-2816. doi: 10.1038/ismej.2016.84

Stal, L. J., and Moezelaar, R. (1997). Fermentation in cyanobacteria. FEMS Microbiol. Rev. 21, 179-211.

Steindler, L., Schwalbach, M. S., Smith, D. P., Chan, F., and Giovannoni, S. J. (2011). Energy starved Candidatus Pelagibacter ubique substitutes light-mediated ATP production for endogenous carbon respiration. PLoS One 6:e19725. doi: 10 . 1371/journal.pone.0019725

Stingl, U., Desiderio, R. A., Cho, J.-C., Vergin, K. L., and Giovannoni, S. J. (2007). The SAR92 clade: an abundant coastal clade of culturable marine bacteria possessing proteorhodopsin. Appl. Environ. Microbiol. 73, 2290-2296. doi: 10. 1128/AEM.02559-06

Strömpl, C., Hold, G. L., Lünsdorf, H., Graham, J., and Gallacher, S. (2003). Oceanicaulis alexandrii gen. nov., sp. nov., a novel stalked bacterium isolated from a culture of the dinoflagellate Alexandrium tamarense (Lebour) Balech. Int. J. Syst. Evol. Microbiol. 53, 1901-1906. doi: 10.1099/ijs.0.02635-0

Tan, J., Pu, Z., Ryberg, W. A., and Jiang, L. (2015). Resident-invader phylogenetic relatedness, not resident phylogenetic diversity, controls community invasibility. Am. Nat. 186, 59-71. doi: 10.1086/681584

Tan, K. S. (2008). New insights on classification, identification, and clinical relevance of Blastocystis spp. Clin. Microbiol. Rev. 21, 639-665. doi: 10.1128/ CMR.00022-08

Thompson, A. W., Foster, R. A., Krupke, A., Carter, B. J., Musat, N., Vaulot, D., et al. (2012). Unicellular cyanobacterium symbiotic with a single-celled eukaryotic alga. Science 337, 1546-1550. doi: 10.1126/science.1222700

Thrash, J. C., Cho, J.-C., Vergin, K. L., Morris, R. M., and Giovannoni, S. J. (2010). Genome sequence of Lentisphaera araneosa HTCC2155T, the type species of the order Lentisphaerales in the phylum Lentisphaerae. J. Bacteriol. 192, 2938-2939. doi: 10.1128/JB.00208-10

van Kraaij, C., de Vos, W. M., Siezen, R. J., and Kuipers, O. P. (1999). Lantibiotics: biosynthesis, mode of action and applications. Nat. Prod. Rep. 16, 575-587. doi: $10.1039 / \mathrm{a} 804531 \mathrm{c}$

Vavourakis, C. D., Andrei, A. S., Mehrshad, M., Ghai, R., Sorokin, D. Y., and Muyzer, G. (2018). A metagenomics roadmap to the uncultured genome diversity in hypersaline soda lake sediments. Microbiome 6:168. doi: 10.1186/ s40168-018-0548-7

Vincenzini, M., De Philippis, R., Sili, C., and Materassi, R. (1990). Studies on exopolysaccharide release by diazotrophic batch cultures of Cyanospira capsulata. Appl. Microbiol. Biotechnol. 34, 392-396. doi: 10.1007/bf001 70066

Waters, E., Hohn, M. J., Ahel, I., Graham, D. E., Adams, M. D., Barnstead, M., et al. (2003). The genome of Nanoarchaeum equitans: insights into early archaeal evolution and derived parasitism. Proc. Natl. Acad. Sci. U. S. A. 100, 12984-12988.

Wegner, C.-E., Richter-Heitmann, T., Klindworth, A., Klockow, C., and Richter, M. (2013). Expression of sulfatases in Rhodopirellula baltica and the diversity of sulfatases in the genus Rhodopirellula. Mar. Genomics 9, 51-61. doi: 10.1016/ j.margen.2012.12.001

Wisniewski, J. R., Zougman, A., Nagaraj, N., and Mann, M. (2009). Universal sample preparation method for proteome analysis. Nat. Methods 6, 359-362.

Yakimov, M. M., Timmis, K. N., and Golyshin, P. N. (2007). Obligate oil-degrading marine bacteria. Curr. Opin. Biotechnol. 18, 257-266. doi: 10.1016/j.copbio. 2007.04.006

Zorz, J., Richardson, W. D., Laventure, A., Haines, M., and Cieplechowicz, E. (2021). Light manipulation using organic semiconducting materials for enhanced photosynthesis. Cell Rep. Phys. Sci. 2:100390.

Zorz, J. K., Sharp, C., Kleiner, M., Gordon, P. M. K., Pon, R. T., Dong, X., et al. (2019). A shared core microbiome in soda lakes separated by large distances. Nat. Commun. 10:4230. doi: 10.1038/s41467-019-12195-5

Conflict of Interest: The authors declare that the research was conducted in the absence of any commercial or financial relationships that could be construed as a potential conflict of interest.

Publisher's Note: All claims expressed in this article are solely those of the authors and do not necessarily represent those of their affiliated organizations, or those of the publisher, the editors and the reviewers. Any product that may be evaluated in this article, or claim that may be made by its manufacturer, is not guaranteed or endorsed by the publisher.

Copyright (C) 2022 Ataeian, Liu, Kouris, Hawley and Strous. This is an open-access article distributed under the terms of the Creative Commons Attribution License (CC BY). The use, distribution or reproduction in other forums is permitted, provided the original author(s) and the copyright owner(s) are credited and that the original publication in this journal is cited, in accordance with accepted academic practice. No use, distribution or reproduction is permitted which does not comply with these terms. 